\title{
A Regional Climate Simulation Study Using WRF-ARW Model over Europe and Evaluation for Extreme Temperature Weather Events
}

\author{
Hari Prasad Dasari, ${ }^{1}$ Rui Salgado, ${ }^{2}$ Joao Perdigao, ${ }^{2}$ and Venkata Srinivas Challa ${ }^{3}$ \\ ${ }^{1}$ Centro de Geofísica, Universidade de Évora, 7000 Evora, Portugal \\ ${ }^{2}$ Departamento de Física, Centro de Geofísica, Escola de Ciências e Tecnologia, Universidade de Évora, 7000 Evora, Portugal \\ ${ }^{3}$ Radiological Safety and Environment Group, Indira Gandhi Center for Atomic Research, Kalpakkam 603102, India
}

Correspondence should be addressed to Hari Prasad Dasari; dasarihariprasad@rediffmail.com

Received 7 April 2014; Revised 3 July 2014; Accepted 4 July 2014; Published 2 September 2014

Academic Editor: Helena A. Flocas

Copyright (C) 2014 Hari Prasad Dasari et al. This is an open access article distributed under the Creative Commons Attribution License, which permits unrestricted use, distribution, and reproduction in any medium, provided the original work is properly cited.

\begin{abstract}
In this study regional climate simulations of Europe over the 60-year period (1950-2010) made using a $25 \mathrm{~km}$ resolution WRF model with NCEP 2.5 degree analysis for initial/boundary conditions are presented for air temperature and extreme events of heat and cold waves. The E-OBS $25 \mathrm{~km}$ analysis data sets are used for model validation. Results suggest that WRF could simulate the temperature trends (mean, maximum, minimum, seasonal maximum, and minimum) over most parts of Europe except over Iberian Peninsula, Mediterranean, and coastal regions. Model could simulate the slight fall of temperatures from 1950 to 1970 as well as steady rise in temperatures from 1970 to 2010 over Europe. Simulations show occurrence of about $80 \%$ of the total heat waves in the period $1970-$ 2010 with maximum number of heat/cold wave episodes over Eastern and Central Europe in good agreement with observations. Relatively poor correlations and high bias are found for heat/cold wave episodes over the complex topographic areas of Iberia and Mediterranean regions where land surface processes play important role in local climate. The poor simulation of temperatures over the above regions could be due to deficiencies in representation of topography and surface physics which need further sensitivity studies.
\end{abstract}

\section{Introduction}

Climate change is a widely discussed environmental issue in recent times. Increase in the greenhouse gases due to consumption of fossil fuels, increase in deforestation, and anthropogenic activities have been attributed as the causes for the present changes in the temperature and rainfall patterns [1-4]. Variations in temperature and precipitation on global, regional, and local scales are the issues of interest for their impact on the ecosystem. The projections of mean atmospheric temperature and precipitation during the 21st century indicate ecological, economic, and social disruptions are likely to occur in the future. Some of the projected changes [5] in European climate include (i) increase of water vapour transport from low to high latitudes, (ii) changes in atmospheric circulation on longer time scales, (iii) reduction of snow cover during winter in the northeastern part of the continent, (iv) drying of the soil in summer in the Mediterranean and Central European regions, and (v) increase in annual mean temperatures with higher warming in winters in northern Europe and in summers in the Mediterranean area. Studies indicate that the increase of annual mean temperature over Europe will exceed the global warming rate in the 21 st century. Studies indicate that temperatures in winter would increase in northern Europe [6], and temperatures during summer would increase in the Mediterranean area. Hanssen-Bauer et al. [7] have reported that during winter minimum temperatures would increase more than the mean temperature in northern Europe. A recent study by Tebaldi et al. [8] reported that maximum temperatures in summer are likely to increase more than the mean summer temperature in southern and Central Europe. Climate variability on interannual time scale is crucial to understand climate 
impacts on agricultural production systems [9]. The dramatic economic and societal repercussions of the extreme European summer of 2003 and 2010 clearly demonstrate the climate change impacts [10-12]. Atmosphere-ocean coupled general circulation models (AOGCM) facilitate to study large-scale climate extreme events [5]. However, small-scale extreme weather events cannot be resolved by AOGCMs. Regional climate models (RCM) can be used to dynamically downscale and obtain small-scale regional climate information from global climate models [13-16]. Several studies demonstrated the advantages of regional models, with higher spatial and temporal resolution, for regional climate prediction by suitably integrating them with the boundary conditions provided by the AOGCMs [17-20]. The RCMs provide localized, high resolution information and can simulate the effects of complex topography with large landwater contrasts to derive regional climate consistent with the large-scale climate simulated by the AOGCM used as forcing [21].

A number of models such as RegCM, CSU/RAMS, and UKMO have been developed for regional climate studies [22-27]. RCMs due to both higher resolution and improved physics are able to better resolve mesoscale effects associated with topography (coastlines, mountains, water bodies, vegetation etc.,), the local climate, and the related influence on the temperature and precipitation systems ([28-38] among others). The ENSEMBLES project in Europe deals with the scientific aspects of regional climate change and with the objectives of understanding model uncertainties [39]. Some of the studies in the project are focused on the skill of the model performance with respect to precipitation and temperature over different parts of Europe and also Europe as a whole [36, 40-47]. A few studies attempted the long-term climate investigation on a regional scale at a high resolution using WRF over certain specific regions or complex topographic areas in Europe $[48,49]$ for limited period of about 2 to 3 decades. However, an analysis of temperature variations over various parts requires long-term simulations over entire Europe using regional models with a computationally affordable resolution.

The objective of this work is to study the fidelity of Advanced Research Weather Research and Forecast (WRFARW) regional model to simulate the temperature patterns in Europe over the 60-year period (1950-2010) with reference to the warm and cold seasons, their long-term variability, and subregional variations and to improve the knowledge of the temperature variations, especially of the extreme heat/cold wave events on a regional scale over Europe. The WRF-ARW regional model is chosen as it has the sophisticated physics for land-surface, planetary boundary layer, radiation, and other atmospheric processes that are important to simulate the regional small-scale processes.

\section{Model and Data}

ARW is a limited area, primitive equation, nonhydrostatic, and terrain following sigma coordinate model. The model is configured with two-way interactive nested domains with horizontal grid spacing of $75 \mathrm{~km}$ in the outer domain and $25 \mathrm{~km}$ in the inner domain (Figure 1). The details of model domains and physics are presented in Table 1. The outer domain covers the region encompassing the entire Europe and parts of Atlantic Ocean, Southern Arctic, and so forth. The three-dimensional initial atmospheric fields and the time varying boundary conditions are derived from the National Centers for Environmental Prediction (NCEP) global reanalysis fields [50] available at 2.5 degree latitude/longitude resolution and at 6-hour interval. The model is integrated continuously for 13 months, starting from 00UTC of 1 May for each year from 1950 for the entire 6 decades of 1950-2010; although model can be initialized in any season during a year, we have chosen 00UTC 1 May as starting time as it corresponds to a summer weak synoptic condition over Europe. The model outputs are generated at every 3-hour interval and model results are analyzed from the $25 \mathrm{~km}$ resolution domain. The first one month simulation of each year run is considered as model spinup time and hence neglected from analysis. The model physics is chosen as the WSM3 explicit microphysics, Dudhia scheme [51] for shortwave radiation processes, RRTM scheme for long wave radiation processes [52], the nonlocal YSU scheme for PBL turbulence [53, 54], multilayer soil scheme for surface processes, and the Betts-Miller-Janjic $[55,56]$ for convection. The soil scheme solves the thermal diffusivity equation using 5 soil layers and the energy budget includes radiation, sensible, and latent heat fluxes. It treats the snow-cover, soil moisture as fixed quantities with a land use and seasondependent constant value. The terrain, land use, and soil data are interpolated to the model grids from USGS global elevation, 24 category USGS vegetation data and 17 category FAO soil data with suitable spatial resolution (arc 5 minutes) to define the lower boundary conditions. The maximum and minimum temperatures are computed from the 3-hour interval outputs. The model results for the whole 60-year period (1950 to 2010) are compared with E-OBS V7.0 [57] observations available at 0.25 degree. The E-OBS is the only source of data available in the public domain for comparative analysis. As E-OBS data has the same resolution $(25 \mathrm{~km})$ as that of ARW 2nd domain no interpolation is applied while comparing the results. Also no corrections for bias in E-OBS data have been applied. Spatial statistics between observations and model produced mean, minimum, and maximum temperatures are generated for entire period as a whole and on different seasons. The number of heat waves and cold waves is computed from E-OBS data and simulations and discussed.

\section{Statistical Methods}

In the present study the framework of model evaluation by Murphy and Winkler [58] is followed. To assess the long-term performance several statistical indices are estimated. They include Pearson correlation coefficient (COR), normalized BIAS (NBIAS), normalized root mean square error (NRMSE), normalized mean absolute error (NMAE), 


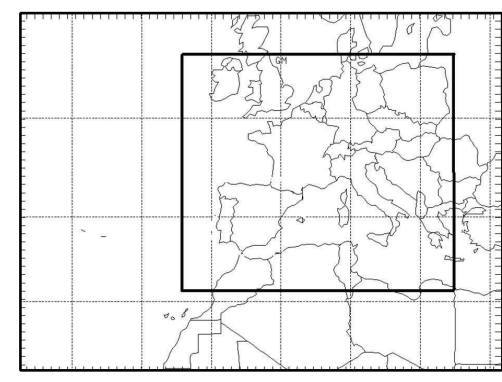

(a)

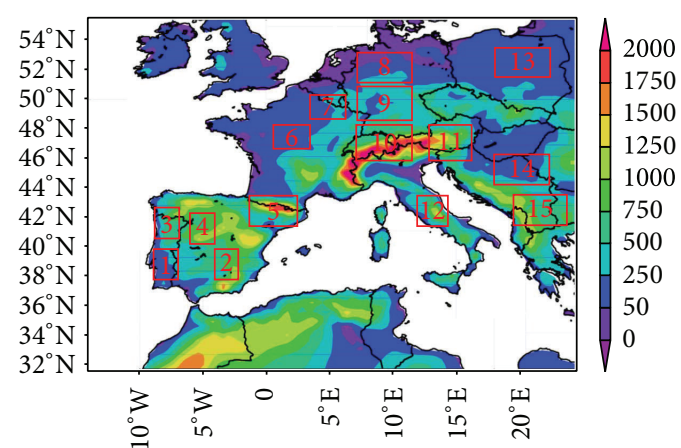

(b)

FIgURE 1: (a) Model domains used for this study (b) topography along with chosen region.

TABLE 1: Model details and configuration.

\begin{tabular}{lcc}
\hline Model name & \multicolumn{2}{c}{ NCEP/NCAR ARW } \\
\hline Model type & Primitive equation, nonhydrostatic \\
\hline Vertical resolution & 30 sigma levels; model top-10 hPa \\
\hline Horizontal resolution & $75 \mathrm{~km}$ & $25 \mathrm{~km}$ \\
\hline Domain of integration & $38.5 \mathrm{~W}-30.83 \mathrm{E}$ & $13.585 \mathrm{~W}-24.8351 \mathrm{E}$ \\
& $21.82 \mathrm{~N}-59.75 \mathrm{~N}$ & $31.7935 \mathrm{~N}-55.7455 \mathrm{~N}$ \\
\hline Radiation scheme & CAM scheme for short wave radiation. \\
& CAM scheme for long wave radiation \\
\hline Land-surface scheme & \multicolumn{2}{c}{ Thermal diffusion scheme } \\
\hline Sea surface temperature & Real sea surface temperatures \\
\hline Convection scheme & Grell-Devenyi ensemble scheme \\
\hline PBL scheme & \multicolumn{2}{c}{ YSU scheme } \\
\hline Explicit moisture scheme & WSM 3-class simple ice scheme \\
\hline
\end{tabular}

and normalized standard deviation (NSTDEV) as given below:

$$
\begin{aligned}
\mathrm{COR} & =\frac{\sum_{i=1}^{n}\left(f_{i}-\bar{f}\right)\left(o_{i}-\bar{o}\right)}{\sqrt{\sum_{i=1}^{n}\left(f_{i}-\bar{f}\right)^{2}} \sqrt{\sum_{i=1}^{n}\left(o_{i}-\bar{o}\right)^{2}}}, \\
\mathrm{BIAS} & =\frac{1}{n} \sum_{i=1}^{n}\left(f_{i}-o_{i}\right)=\bar{f}-\bar{o}, \\
\mathrm{STDEV} & =\sqrt{S_{f}^{2}+S_{o}^{2}-2 S_{f} S_{o} r_{f o}}, \\
\mathrm{RMSE} & =\sqrt{\frac{\left(\sum_{i=1}^{n}\left(f_{i}-o_{i}\right)^{2}\right)}{n}}, \\
\mathrm{RANGE} & =\frac{1}{n} \sum_{i=1}^{n}\left|f_{i}-o_{i}\right|, \\
& \left(o_{\max , i=1, n}-o_{\min , i=1, n}\right) .
\end{aligned}
$$

From (2) to (5), the normalized values for each statistical index can be obtained by the following formulas:

$$
\begin{gathered}
\text { NBIAS }=\left(\frac{\text { BIAS }}{\text { RANGE }}\right) \times 100, \\
\text { NSTDEV }=\left(\frac{\text { STDEV }}{\text { RANGE }}\right) \times 100, \\
\text { NRMSE }=\left(\frac{\text { RMSE }}{\text { RANGE }}\right) \times 100, \\
\text { NMAE }=\left(\frac{\text { MAE }}{\text { RANGE }}\right) \times 100 .
\end{gathered}
$$

Also another coefficient called Nash-Sutcliffe efficiency (NSE) coefficient commonly employed to assess the predictive power of hydrological model is also evaluated. It is defined as

$$
\mathrm{NSE}=1-\frac{\left((1 / n) \sum_{i=1}^{n}\left(f_{i}-o_{i}\right)^{2}\right)}{\left((1 / n) \sum_{i=1}^{n}\left(f_{i}-\bar{f}\right)^{2}\right)}
$$

where $O_{i}$ is an observed variable, $f_{i}$ is a modeled variable, overbar represents average over all the data, and " $n$ " is the total number of locations that predicted data are compared against observations. Bias is a measure of mean error for a continuous variable, $\mathrm{SD}$ is the standard deviation of the error $(f-o)$, where $S_{f}$ is the standard deviation in forecasts, $S_{o}$ is the standard deviation in observations, and $r_{f_{o}}$ is the correlation between the forecasts and observations. The Nash-Sutcliffe efficiency (NSE) coefficient ranges from negative infinity to one. An efficiency of 1 corresponds to a perfect match between observed and modeled values. The NSE ranges $0-0.3,0.3-0.6,0.6-0.8$, and $>0.8$ indicate the model performance is poor, reasonable, good, and excellent, respectively $[59,60]$. Specifically, MAE is less influenced by large errors and also does not depend on the mean error. The normalized values of BIAS, STDEV, and MAE are often expressed in percentages. The NBIAS is a measure of the over- or underprediction of a variable. Positive values indicate overprediction and negative values indicate underprediction. Similarly NSTDEV and NMAE are also expressed in percentages but with smaller values representing better agreement 
between observed and modelled values. In this study we used the COR, NBIAS, NMAE, and NSTDEV to validate the model performance against observations.

\section{Results and Discussion}

The results are presented in three sections. The first section focuses on 60-year mean values of minimum, maximum, and mean temperatures and corresponding spatial statistics between E-OBS (referred hereafter as observations) and corresponding model values. In the second section the seasonal means for winter (December, January, and February), spring (March, April, and May), summer (June, July, and August), and autumn (September, October, and November) are produced for all 6 decades and model performance evaluated by comparisons with corresponding observations. Finally, a comparative analysis is made over different zones in Europe for heat waves and cold waves (Figure 1). A total of 15 zones are considered for the extreme value analysis wherein the zones are selected based on characteristics of topography. These different zones are distributed over Iberian Peninsula, Mediterranean region, Central Europe, and Eastern Europe. Zones 6-8 and 13-14 are located in the northern and western Europe with moderate altitude of $\leq 250 \mathrm{~m}$ above mean sea level (AMSL), zones 2-5 are located in Iberian Peninsula with mean altitude of 250 to $1000 \mathrm{~m}$ AMSL, zones 10 and 11 are located in the high altitude ( $\geq 1500 \mathrm{~m}$ AMSL) Alps mountain region, and zone 12 with moderate altitude is located in the Italian peninsula. The heat wave conditions are analysed from daily maximum temperatures from summer months and cold waves from daily minimum temperatures of winter seasons as per their definition prescribed by World Meteorological Organization [61].

4.1. Analysis of Daily Temperatures. The daily mean, maximum, and minimum temperatures from simulation and observations are presented in this section. The spatial distribution of 60-year mean daily mean temperatures and corresponding model values is presented in Figures 2(a) and 2(b). It is seen that the spatial distribution of model mean temperatures is in good agreement with observations. Lesser temperatures are noted over Iberian Peninsula relative to observations. Normalized values of BIAS, MAE, STDEV, and RMSE between model and observed mean daily temperatures for entire 60-year period are presented in Figures 2(c) and 2(f). The spatial NBIAS distribution (Figure 2(c)) indicates the model underestimates air temperature by around -5 to $-10 \%$ over the Iberian Peninsula and overestimates air temperatures by $+15 \%$ over Alps Mountain. In other parts of Europe the bias is about -5 to $5 \%$. Similarly the NMAE over Iberian Peninsula region is about $5-10 \%$ and about $10-$ $25 \%$ over Alps region (Figure 2(d)). The NSTDEV between observed and model simulated mean temperatures is about $5-10 \%$ in most of Europe except the coast line in Eastern Europe where the NSTDEV is about $\sim 20 \%$ (Figure $2(\mathrm{e})$ ). The NRMSE in mean temperature is about $10-15 \%$ over the Iberian Peninsula and 15-25\% over Alps, a few areas in Italy and Iberia, while the rest of Europe has NRMSE of $5-10 \%$ (Figure $2(\mathrm{f})$ ). The spatial temperature correlations (Figure 2(g)) obtained at 99\% significance indicate high correlations $(>0.9)$ in Eastern Europe, moderate correlations (0.85-0.9) in western and central parts, and relatively less correlations (0.7-0.8) in coastal parts. The low correlations are associated with high NSTDEV as expected. Overall reasonably good correlations $(>0.7)$ are obtained for surface air temperature over most parts of Europe. All the above statistical indices clearly show that the model simulated daily mean temperatures fairly well in the central and eastern parts of the domain and moderately well over the western parts especially over the Iberian Peninsula. This is reflected in the Nash coefficient (0.1-0.3 poor; $0.3-0.6$ good; more than 0.6 very good) which has poor values ( 0.01 to 0.3 ) over coastal parts and Iberian region and moderate values (0.3-0.6) over Central and southeastern Europe and higher values $(>0.6)$ over northeastern Europe. The obtained Nash coefficient (Figure 2(h)) values indicate the model performance is fairly good over most parts of Europe with values of $\geq 0.3$ and relatively poor over Alps region and few west coastal parts The above results indicate the model produces a warm bias in the Eastern Europe, Alps, and few central parts, and cold bias over most of Iberian Peninsula, Italy, and many western parts.

To examine the simulation of time cycle of temperatures we analysed the maximum and minimum daily temperatures (in Figures 3 and 4). The spatial patterns of simulated mean daily maximum and mean daily minimum temperatures are noted to be in good agreement with those derived from observations. The model slightly underestimates maximum temperature over Iberian region and simulates well over other parts of Europe (Figures 3(a) and 3(b)). The NBIAS values are in the range of -10 to $10 \%$ over most of Europe. The NBIAS indicates a cold bias $(-5$ to $-10 \%)$ over Iberia, slight cold bias $(-5 \%)$ over western and northern parts, and slight warm bias (5\%) over western Europe, western parts of Italy, and few zones such as Alps. Similarly from other statistical parameters NSTDEV and NRMSE (Figures 3(e) and 3(f)) it is seen that the normalized errors are less than $10 \%$ in most parts of Europe except Iberian Peninsula and Alps region which have normalized RMSE in the range $10-15 \%$ and $15-25 \%$, respectively. Spatial correlations for maximum temperature are fairly good (>0.85) over most parts of Europe except the northwestern areas, western coastal areas, and Alps which have correlations in the range $0.7-0.85$. Correspondingly the Nash coefficient is also poor $(<0.01)$ over limited parts of Iberia and Alps indicating poor simulation of maximum temperatures over those areas. However, the Nash coefficient values (Figure 3(h)) for maximum temperatures are higher relative to mean temperatures. All the above indices show that the simulations for maximum temperature are good over most parts of Iberia and western and Central Europe and relatively better in Eastern Europe. The Correlation coefficient (Figure $3(\mathrm{~g})$ ) values are high $(>0.8)$ over most of the domain with $95 \%$ significance except the west coast of Europe which has slightly lesser correlations $(\sim 0.7)$. Similar spatial trends are noted in 60-year mean daily minimum temperatures (Figures 4(a) and 4(b)) as with maximum temperatures. In most of Eastern Europe including the Iberian region the 


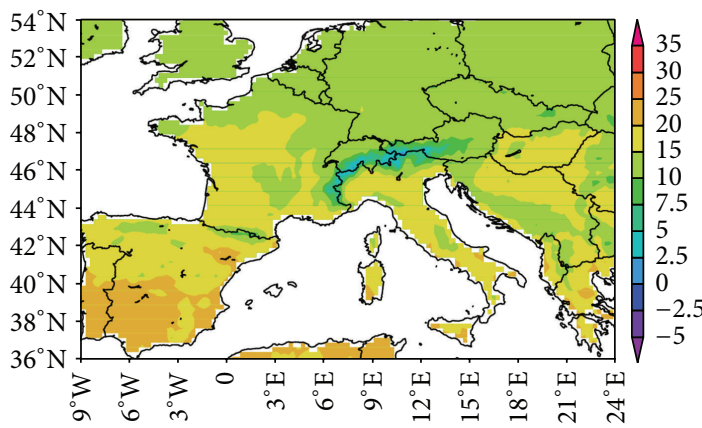

(a) 60-year mean daily mean temperature (OBS)

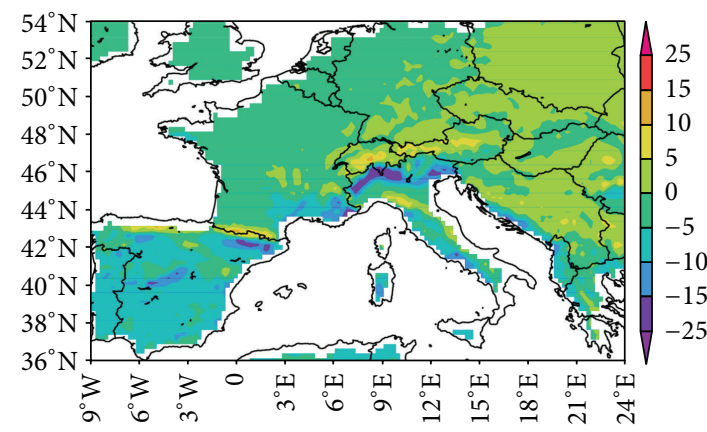

(c) Normalized BIAS for 60-year daily mean temperature (OBS versus model)

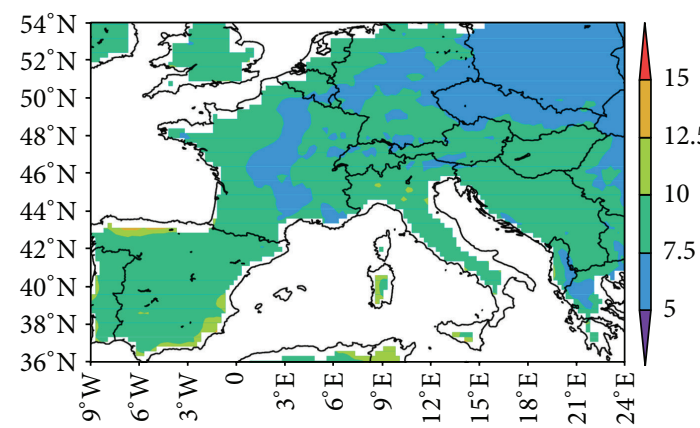

(e) Normalized STDEV for 60-year daily mean temperature (OBS versus model)

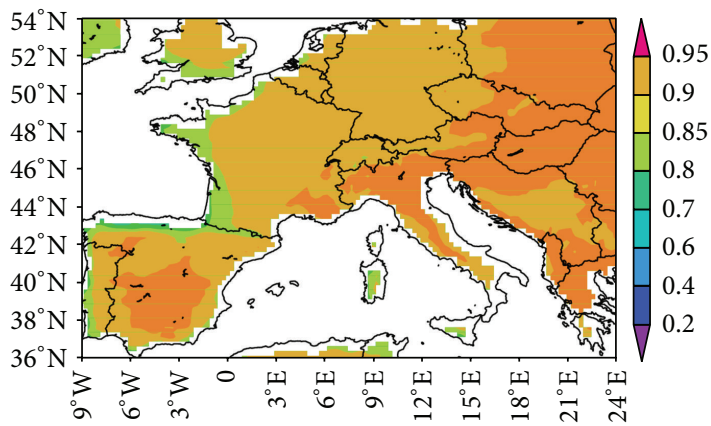

(g) Correlation coefficient for 60-year daily mean temperature (OBS versus model)

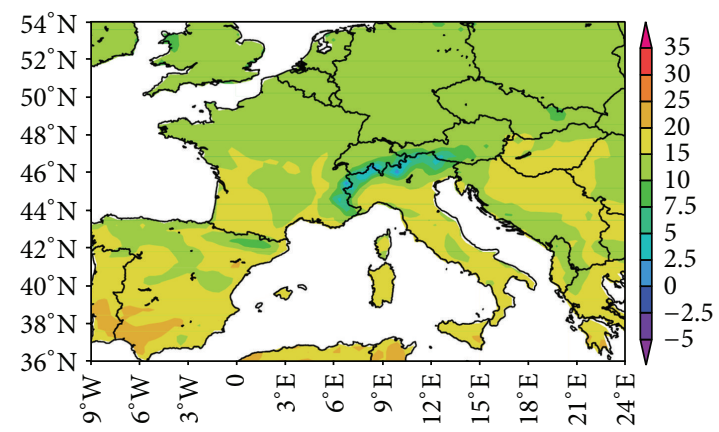

(b) 60-year mean daily mean temperature (model)

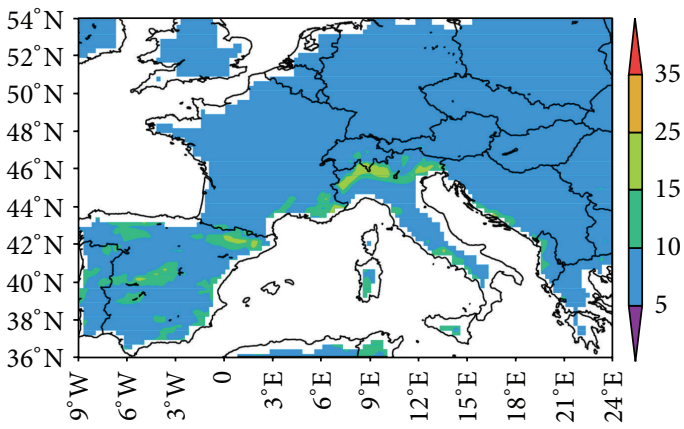

(d) Normalized MAE for 60-year daily mean temperature (OBS versus model)

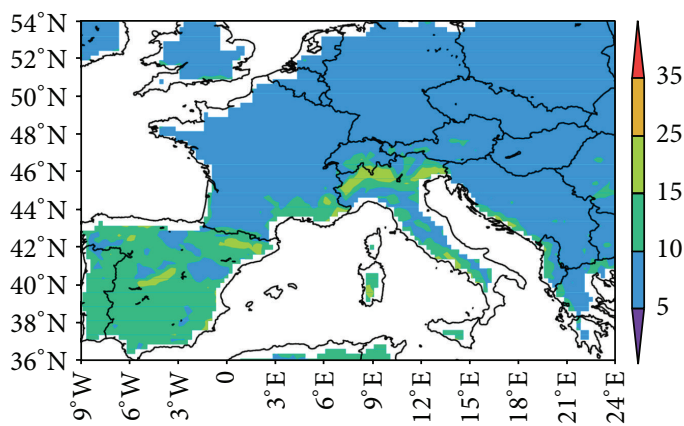

(f) Normalized RMSE for 60-year daily mean temperature (OBS versus model)

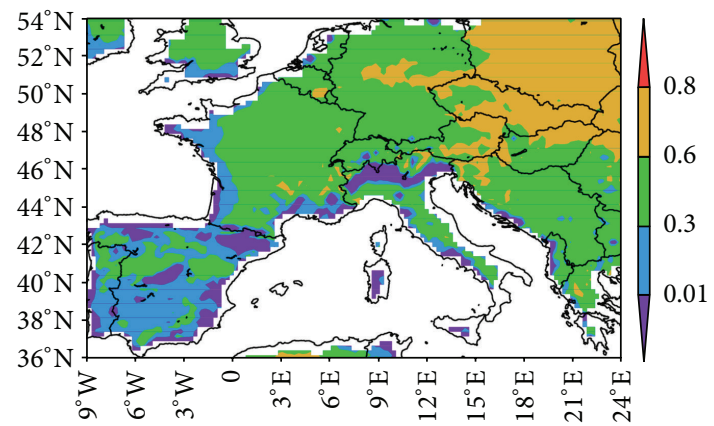

(h) Nash-Sutcliffe coefficient for 60-year daily mean temperature (OBS versus model)

FIGURE 2: 60-year daily mean temperatures at $2 \mathrm{~m}$ height. (a) Mean from OBS and (b) mean from model and (c) normalized BIAS (\%), (d) normalized MAE (\%), (e) normalized STDEV (\%), (f) normalized RMSE (\%), (g) correlation coefficient, and (h) Nash-Sutcliffe coefficient (\%) for 60-year daily mean $2 \mathrm{~m}$ height temperatures between OBS and model. 


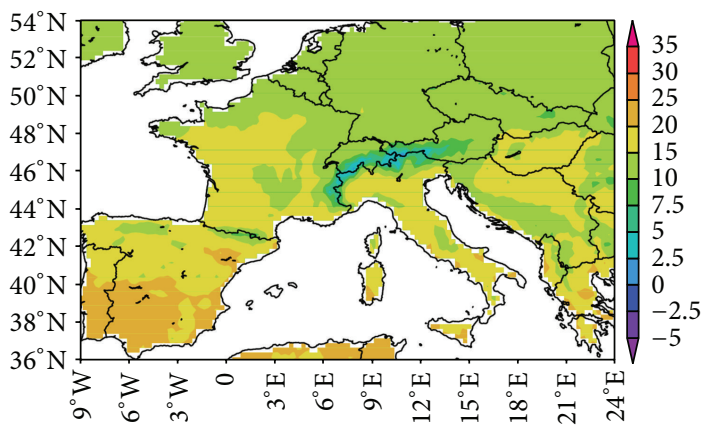

(a) Mean for 60-year daily maximum temperature (OBS)

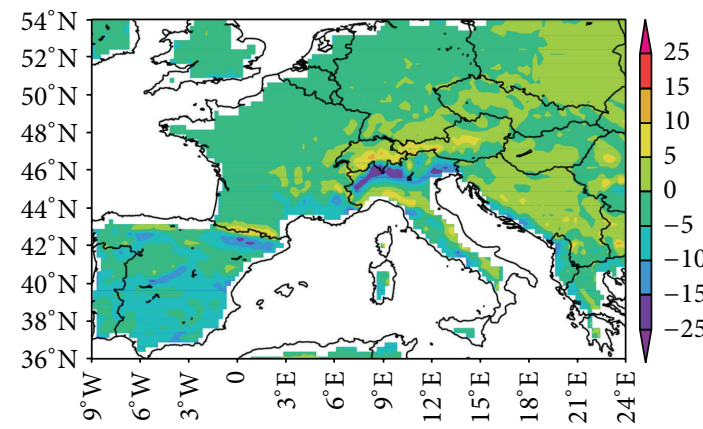

(c) Normalized BIAS for 60-year daily maximum temperature (OBS versus model)

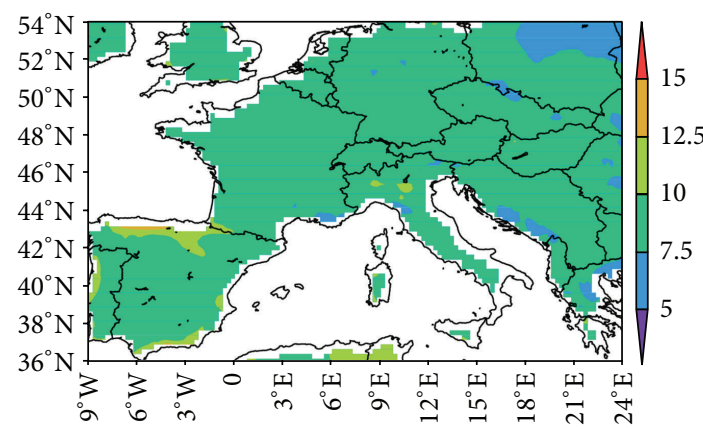

(e) Normalized STDEV for 60-year daily maximum temperature (OBS versus model)

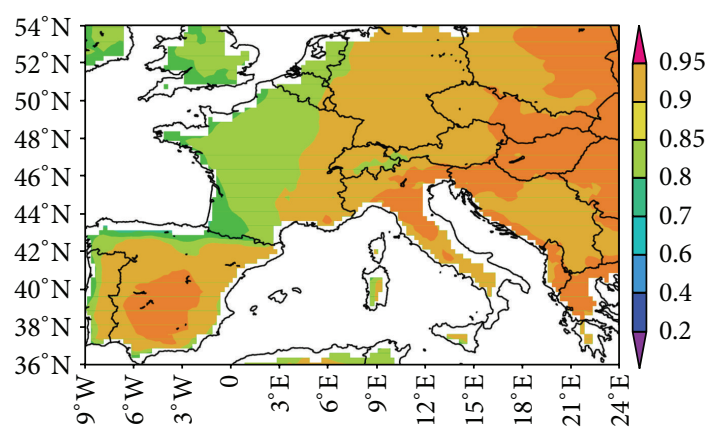

(g) Correlation coefficient for 60-year daily maximum temperature (OBS versus model)

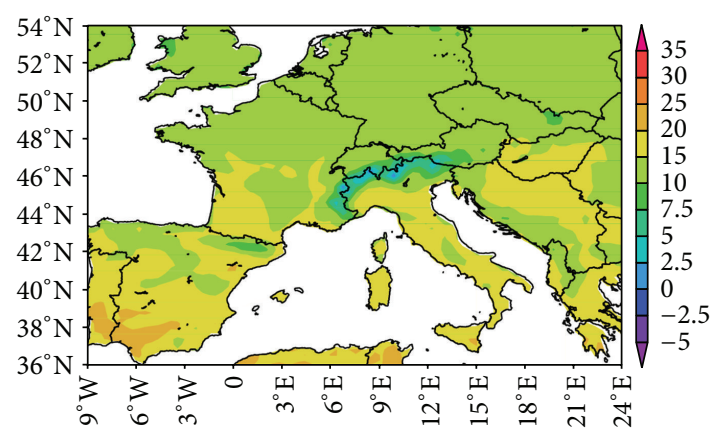

(b) Mean for 60-year daily maximum temperature (model)

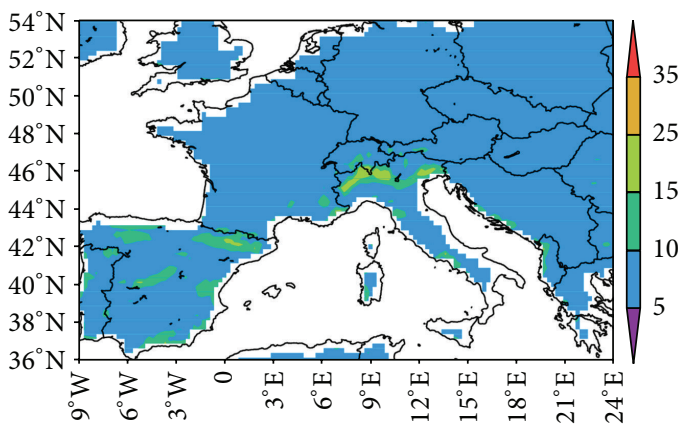

(d) Normalized MAE for 60-year daily maximum temperature (OBS versus model)

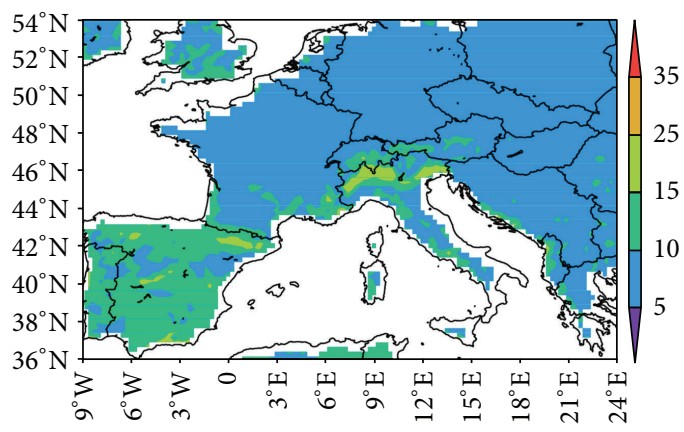

(f) Normalized RMSE for 60-year daily maximum temperature (OBS versus model)

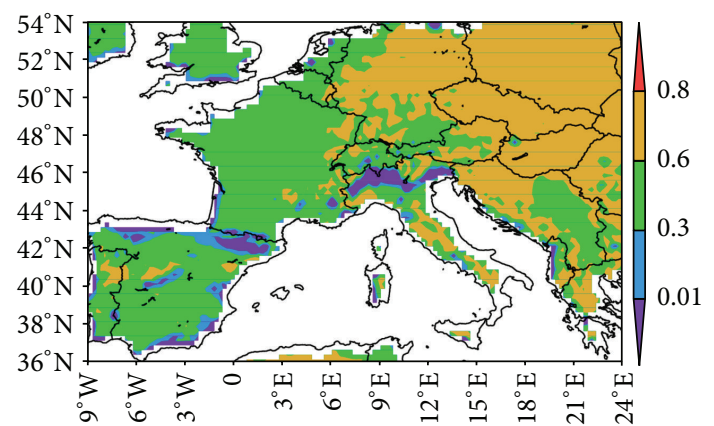

(h) Nash-Sutcliffe coefficient for 60-year daily maximum temperature (OBS versus model)

FIGURE 3: 60-year daily maximum temperatures at $2 \mathrm{~m}$ height. (a) Mean from OBS and (b) mean from model and (c) normalized BIAS (\%), (d) normalized MAE (\%), (e) normalized STDEV (\%), (f) normalized RMSE (\%), (g) correlation coefficient, and (h) Nash-Sutcliffe coefficient (\%) for 60-year daily mean $2 \mathrm{~m}$ height temperatures between OBS and model. 


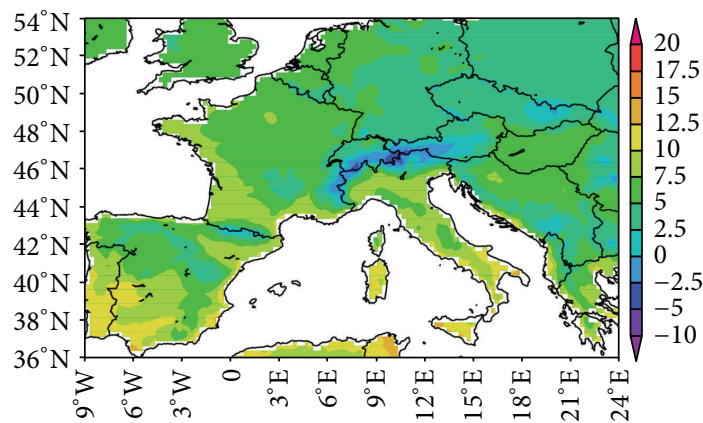

(a) Mean for 60-year daily minimum temperature (OBS)

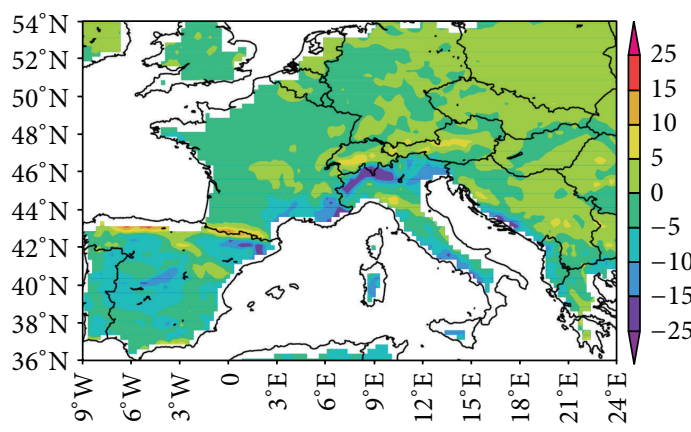

(c) Normalized BIAS for 60-year daily minimum temperature (OBS versus model)

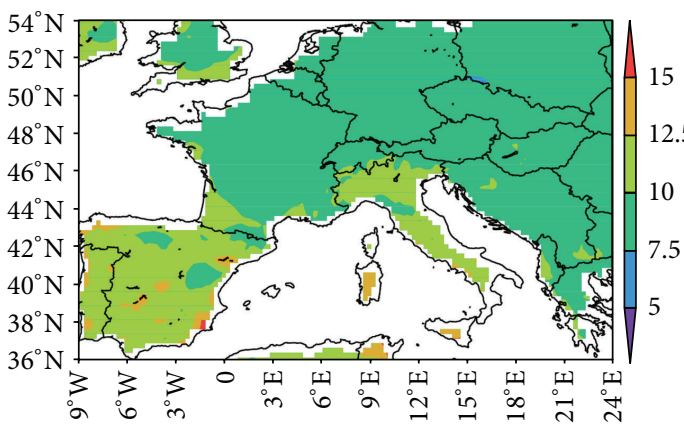

(e) Normalized STDEV for 60-year daily minimum temperature (OBS versus model)

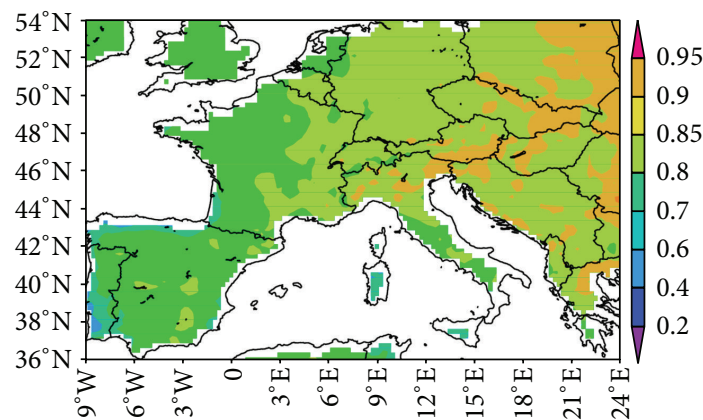

(g) Correlation coefficient for 60-year daily minimum temperature (OBS versus model)

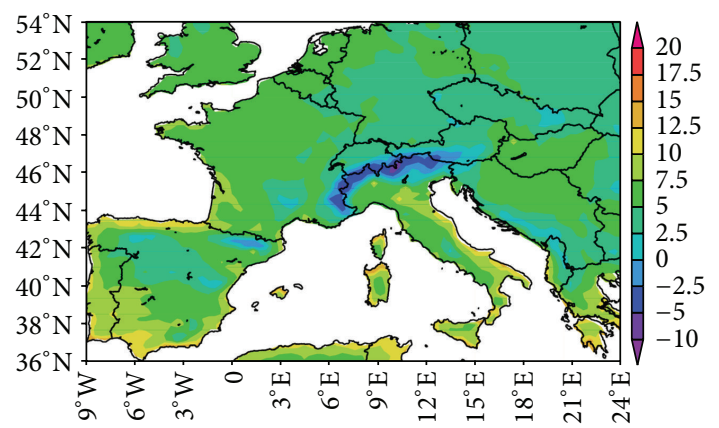

(b) Mean for 60-year daily minimum temperature (model)

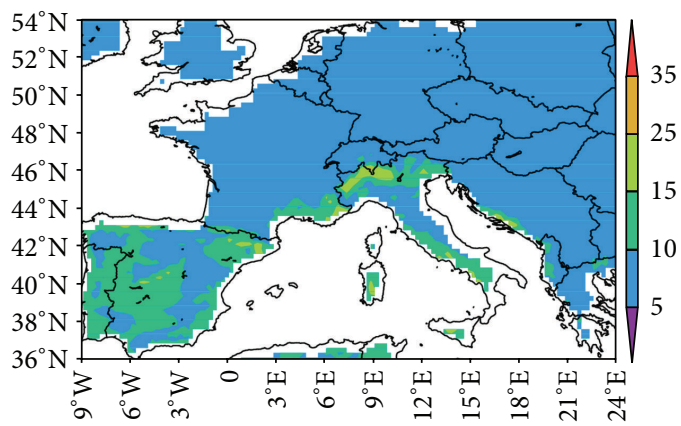

(d) Normalized MAE for 60-year daily minimum temperature (OBS versus model)

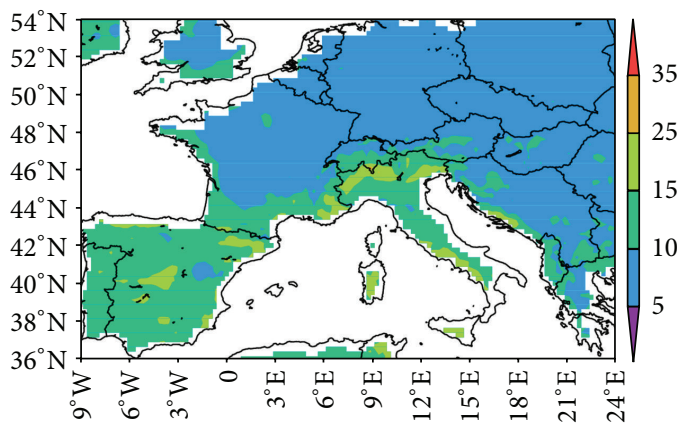

(f) Normalized RMSE for 60-year daily minimum temperature (OBS versus model)

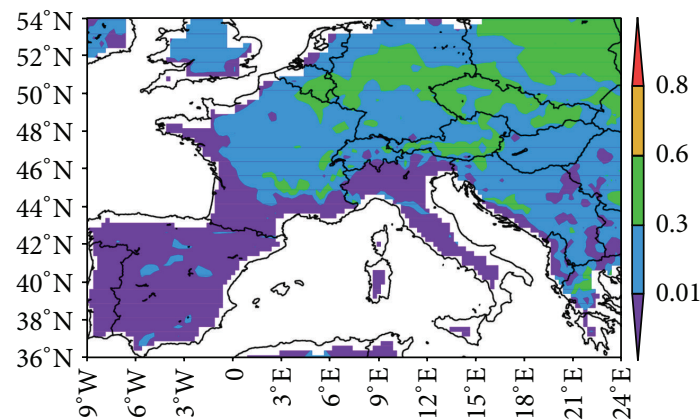

(h) Nash-Sutcliffe coefficient for 60-year daily minimum temperature (OBS versus model)

Figure 4: 60-year daily minimum temperatures at $2 \mathrm{~m}$ height. (a) Mean from OBS and (b) mean from model and (c) normalized BIAS (\%), (d) normalized MAE (\%), (e) normalized STDEV (\%), (f) normalized RMSE (\%), (g) correlation coefficient, and (h) Nash-Sutcliffe coefficient (\%) for 60-year daily mean $2 \mathrm{~m}$ height temperatures between OBS and model. 
underestimation of minimum temperatures is about $0-5 \%$ indicating slight clod bias over these areas. To assess the errors in the simulation of minimum temperatures we analyzed the NBIAS, NMAE, NSTDEV, and NRMSE. The spatial distribution of NBIAS indicates the model underestimates the minimum temperature by nearly $5-10 \%$ over Iberia and by $15 \%$ over Alps and few limited areas in Iberia. Over other parts of Europe the minimum temperatures are overestimated by $5 \%$ thus indicating a slight warm bias. Likewise, the NMAE shows that errors are in the range of $5-15 \%$ over Iberian region, $15-25 \%$ over Alps, and 5-10\% over rest of Europe. The NSTDEV values are moderate (5-10\%) over central, eastern, and northwestern parts of Europe while Iberia and Italy are noted to have relatively poor NSTDEV values (10-15\%). In a similar way the NRMSE values are relatively higher over Iberian region, Italy (about 10-15\%), and Alps (15-25\%) and moderate (5-10\%) over the central, eastern, and northwestern parts of Europe. NRMSE exceeds $15 \%$ at limited regions of Iberia. The correlations for daily minimum temperature are relatively low (0.7-0.8) in Iberian Peninsula, northwestern Europe, improved over Central Europe (0.8-0.85), and high $(>0.85)$ over Eastern Europe. In general the significance of correlations is above $90 \%$ in the Iberian region and it is more than $95 \%$ in other parts of Europe. The Nash coefficient values in the domain confirm the model performance is relatively poor $(<0.01)$ over Iberian Peninsula and Italy, moderate $(0.01-$ $0.3)$ in the northwestern and central Europe, and good $(>0.3)$ over Eastern Europe. Overall correlation coefficients of $>0.8$ and NASH $>0.3$ over Central and Eastern Europe indicate fairly good simulation of minimum temperatures over these parts. Lesser values for correlations $(\sim 0.7)$ and NASH $(\sim 0.01)$ over the northwestern Iberia, Alps, and Italy indicate model's poor performance for minimum temperature simulation over these areas.

Spatial model error statistics distribution for mean, maximum, and minimum temperatures indicates that the model produces a slight cold bias in mean, warm bias in minimum temperatures, and higher cold bias in maximum temperatures. The performance in minimum temperature is relatively poor over Iberia, Italy, and Alps regions and is relatively better over other parts. As compared to minimum temperatures, the maximum and mean temperatures are better simulated over entire Europe. The errors associated with mean temperatures could be partly due to the inherent bias of E-OBs data used for comparison. Model comparison with observation analysis relies on the density of observations employed in the analysis in order to represent realistic spatial patterns in various patterns. Previous studies suggest that high resolution RCMs require a dense observation network for their evaluation (e.g., $[43,62]$, among others). The E-OBS or ECAD gridded observations used in several RCM studies comprise about 20 stations data in Portugal and have been found to be inadequate to represent spatial heterogeneity [47].

4.2. Analysis of Mean Seasonal Temperature. Results from the previous section indicate that there are differences in the simulation of minimum, maximum, and mean temperatures.
Thus it is imperative to study the differences in minimum and maximum temperatures in different seasons (winter, spring, summer, and autumn) as they play a major role in the 60 -year mean values. The mean seasonal temperatures are analyzed below to examine the model behavior on temperature simulation during different seasons.

The 60-year mean seasonal mean temperatures from observations along with temperature difference between model and observation values are presented in Figure 5. The temperature differences indicate that model performance is better in spring (Figures 5(c) and 5(d)) and autumn seasons (Figures 5(g) and 5(h)) as compared to winter and summer seasons where extreme conditions usually prevail. The mean winter temperatures (Figures 5(a) and 5(b)) indicate a warm Bias of 2.5 to $5^{\circ} \mathrm{C}$ over Central and Eastern Europe and slight warm bias of 1 to $2.5^{\circ} \mathrm{C}$ over northern Europe, Mediterranean region, and Iberia. Over Alps and limited areas in Iberia model simulated a cold bias of -1 to $2.5^{\circ} \mathrm{C}$. The above results indicate the model performs better over Iberia and Mediterranean region for winter mean temperatures. In summer season (Figures 5(e) and 5(f)) the model produces a cold bias in mean temperatures over most parts in Europe. It produced a cold bias of -1 to $-2.5^{\circ} \mathrm{C}$ over northeastern Europe and -2.5 to $-5^{\circ} \mathrm{C}$ over western and northern Europe and Italy. An extreme cold bias of $-7.5^{\circ} \mathrm{C}$ is simulated over Alps and southern Iberia. Similarly a cold bias of $-1^{\circ} \mathrm{C}$ over northeastern and southeastern Europe, -1 to $-2.5^{\circ} \mathrm{C}$ over northern and central Europe, and -2.5 to $-5^{\circ} \mathrm{C}$ over Iberia is simulated in autumn season. The bias in the mean temperatures is of the order of -1 to $1^{\circ} \mathrm{C}$ over the entire domain in spring except Alps and limited areas in Iberia where a cold bias of $-2.5^{\circ} \mathrm{C}$ is simulated. Although the spatial seasonal temperature patterns generally agree well with observation patterns, the contours indicate clear cold bias in summer and autumn seasons and warm bias in winter season which indicates that the model generates relatively more errors in simulating the extremities of temperature common to winter and summer seasons than in the other two seasons. Hence, the maximum and minimum temperatures are analyzed in detail to obtain further insight. The seasonal mean of maximum temperatures in different seasons (Figure 6) shows the model simulates a warm bias $\left(2.5\right.$ to $\left.5^{\circ} \mathrm{C}\right)$ in winter maximum temperatures (Figures 6(a) and 6(b)) over northeastern, Central, and Eastern Europe and slight warm bias in Western Europe. In summer the model produced a cold bias $\left(-2.5\right.$ to $-5^{\circ} \mathrm{C}$ ) (Figures 6(e) and $6(f)$ ) over most parts of the domain particularly over Iberian region, Mediterranean and central northern Europe, and southeastern parts of Europe. In both spring and autumn seasons maximum temperatures are simulated in better agreement with corresponding observation means although with a slight cold bias in autumn and warm bias in spring. Thus, temperature simulation in both summer and winter is relatively poor as compared to the remaining two seasons (Figures 6(c), 6(d), 6(g), and 6(h)). Nevertheless, the spatial distribution patterns of mean seasonal temperatures are noted to follow observation pattern. The relatively poor performance for temperatures in summer and winter seasons could be due to deficiencies in the model surface physics 


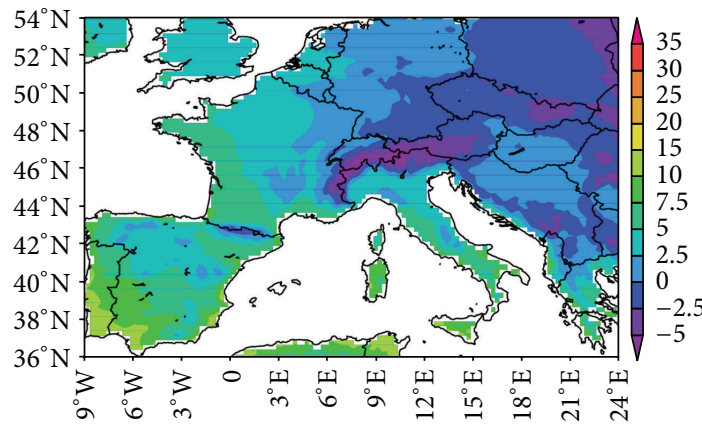

(a) Winter (DJF) season (OBS)

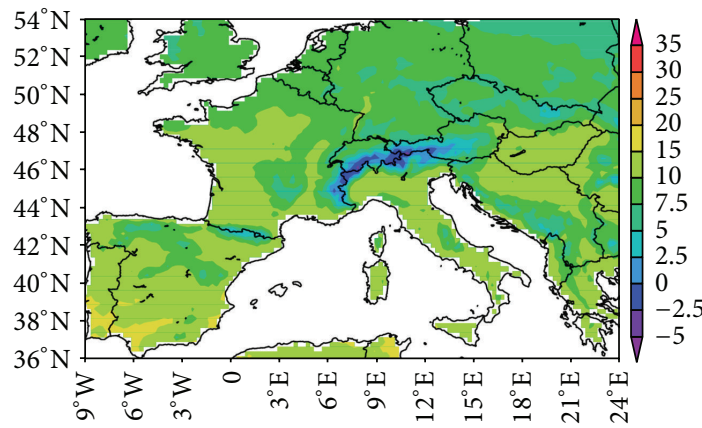

(c) Spring (MAM) season (OBS)

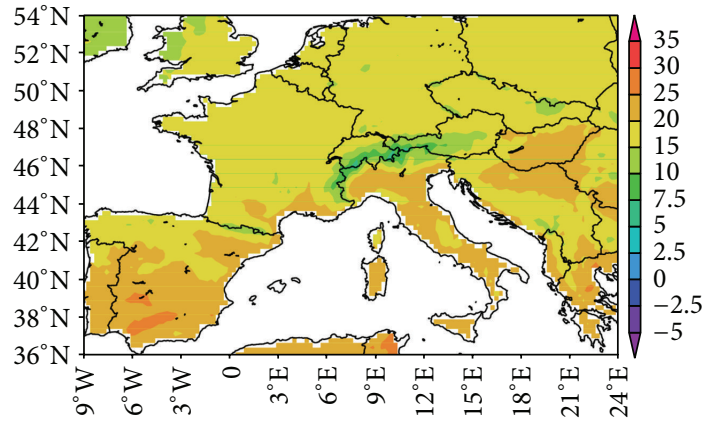

(e) Summer (JJA) season (OBS)

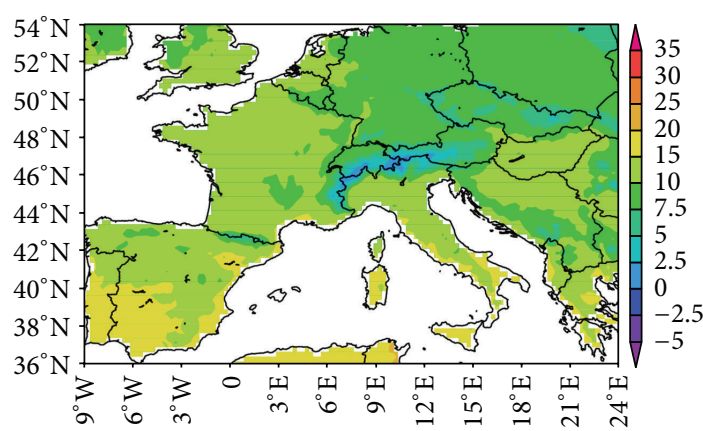

(g) Autumn (SON) season (OBS)

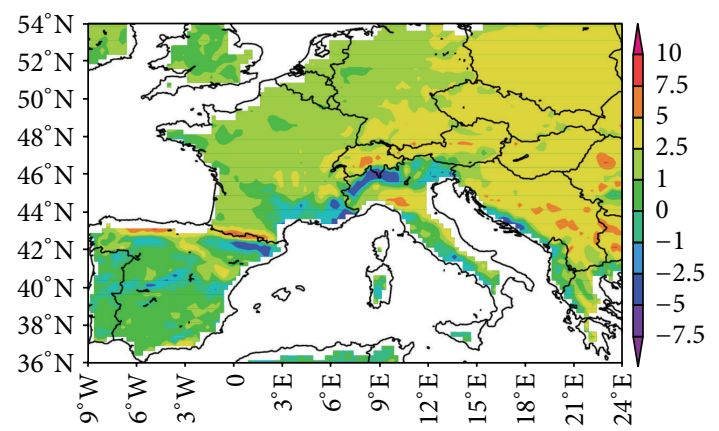

(b) Winter (DJF) season (model-OBS)

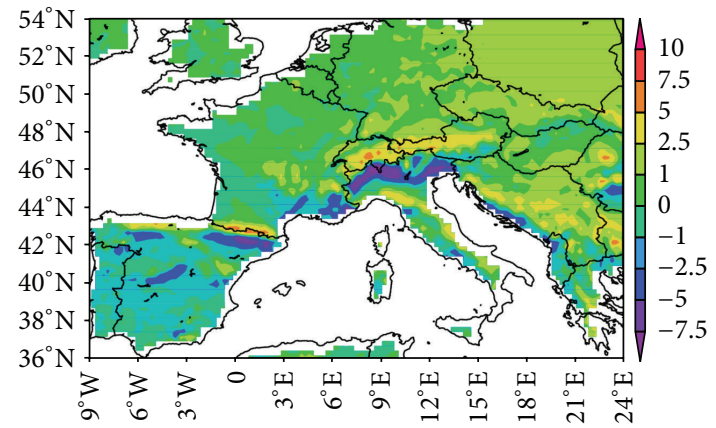

(d) Spring (MAM) season (model-OBS)

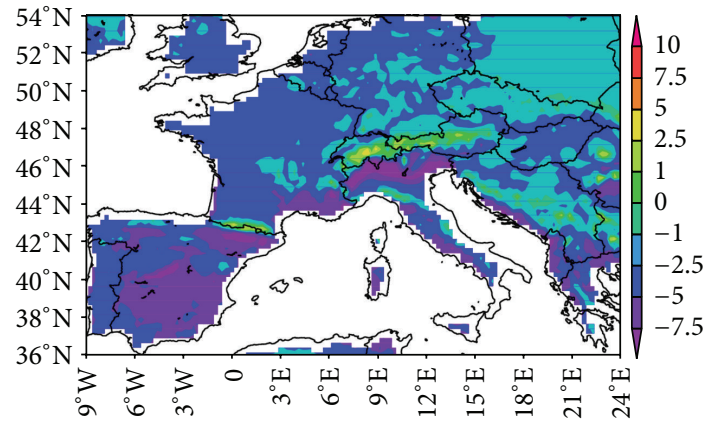

(f) Summer (JJA) season (model-OBS)

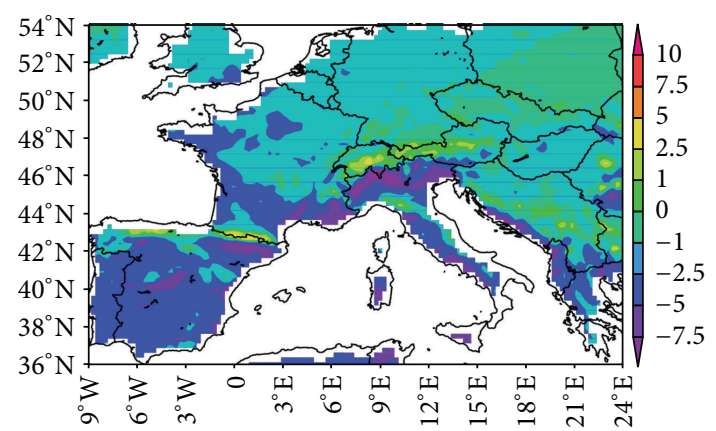

(h) Autumn (SON) season (model-OBS)

FIGURE 5: 60-year mean seasonal mean temperatures at $2 \mathrm{~m}$ height (left panel from OBS and right panel from model-OBS). (a) and (b) for winter season (DJF); (c) and (d) for spring season (MAM); (e) and (f) for summer season (JJA); and (g) and (h) for autumn season (SON). 


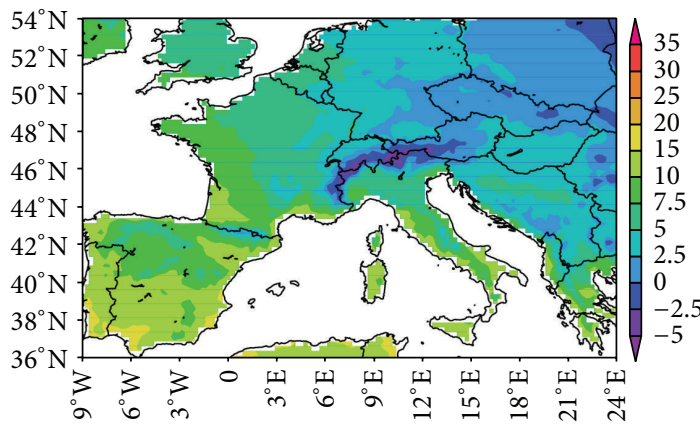

(a) Winter (DJF) season (OBS)

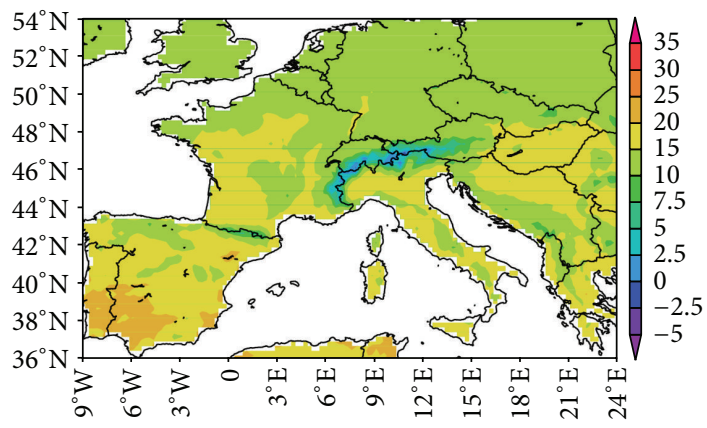

(c) Spring (MAM) season (OBS)

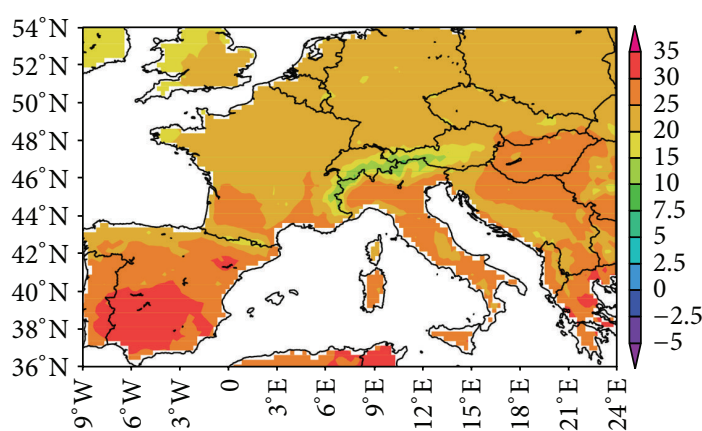

(e) Summer (JJA) season (OBS)

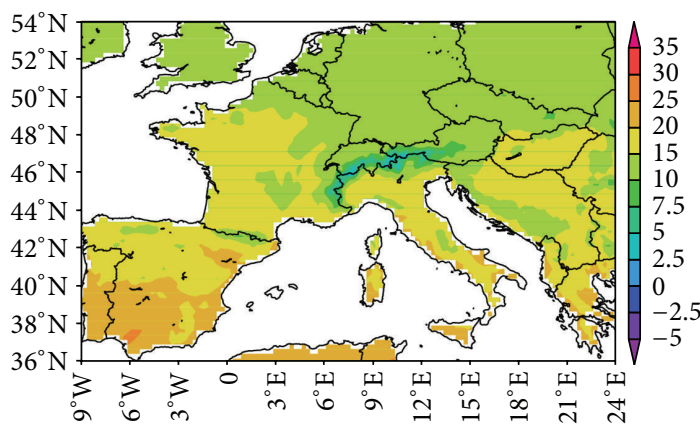

(g) Autumn (SON) season (OBS)

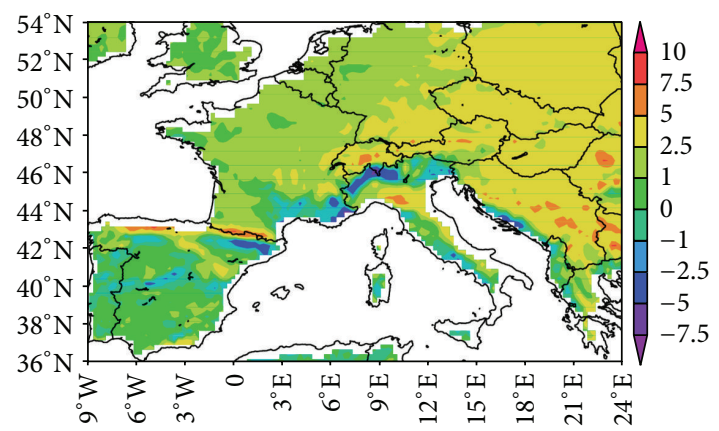

(b) Winter (DJF) season (model-OBS)

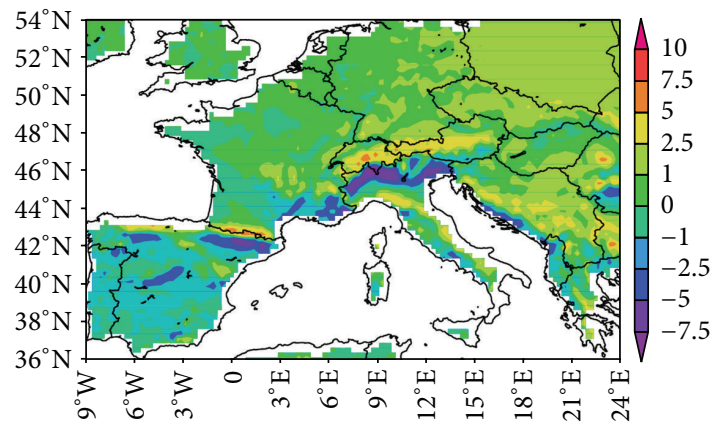

(d) Spring (MAM) season (model-OBS)

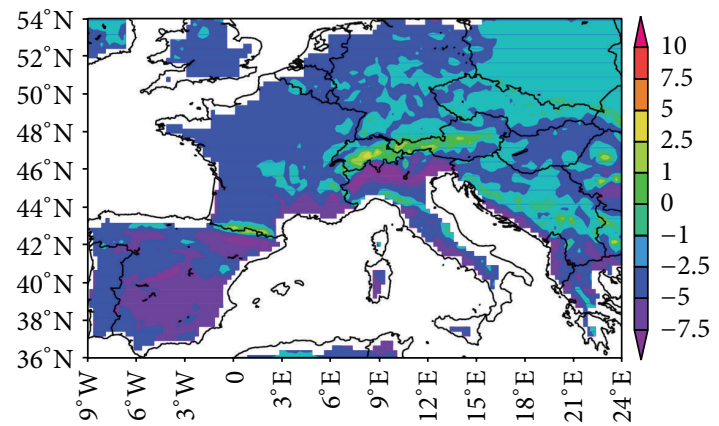

(f) Summer (JJA) season (model-OBS)

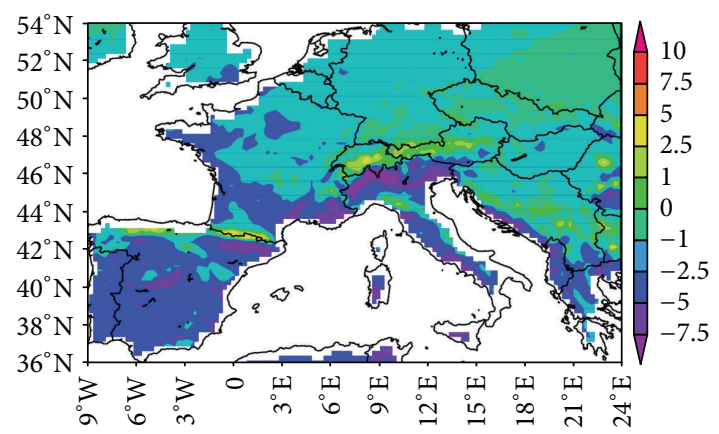

(h) Autumn (SON) season (model-OBS)

FIGURE 6: 60-year mean seasonal maximum temperatures at $2 \mathrm{~m}$ height (left panel from OBS and right panel from model-OBS). (a) and (b) for winter season (DJF); (c) and (d) for spring season (MAM); (e) and (f) for summer season (JJA); and (g) and (h) for autumn season (SON). 


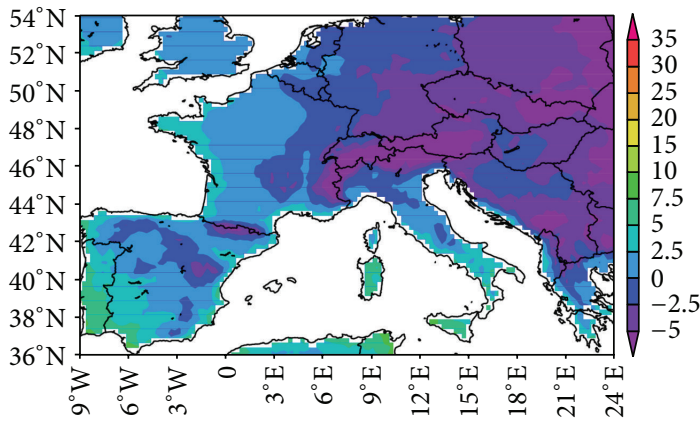

(a) Winter (DJF) season (OBS)

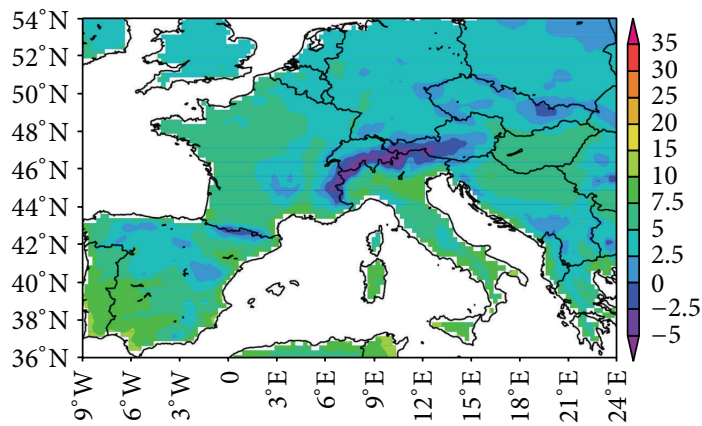

(c) Spring (MAM) season (OBS)

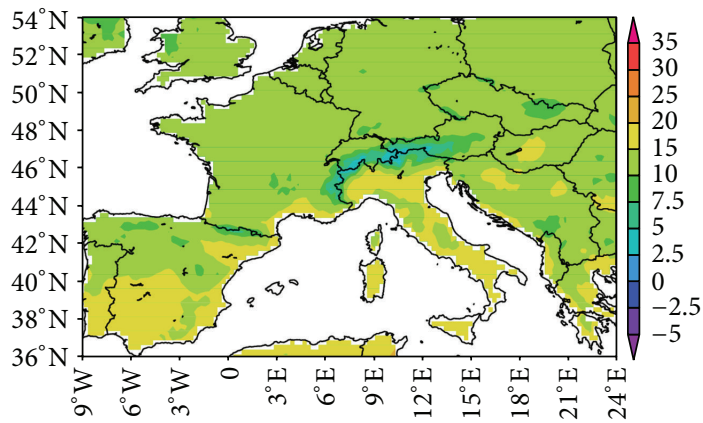

(e) Summer (JJA) season (OBS)

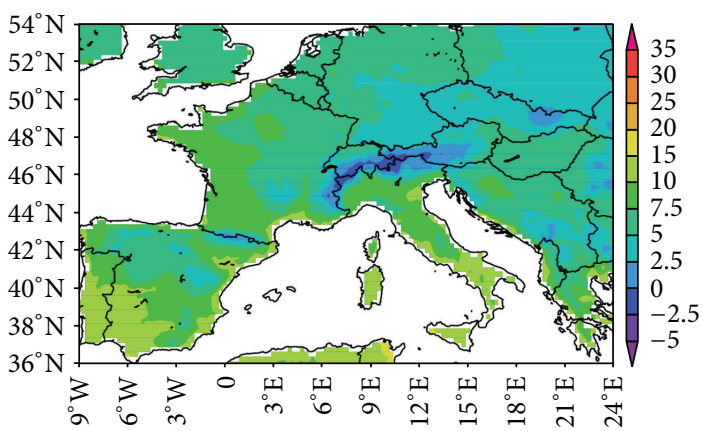

(g) Autumn (SON) season (OBS)

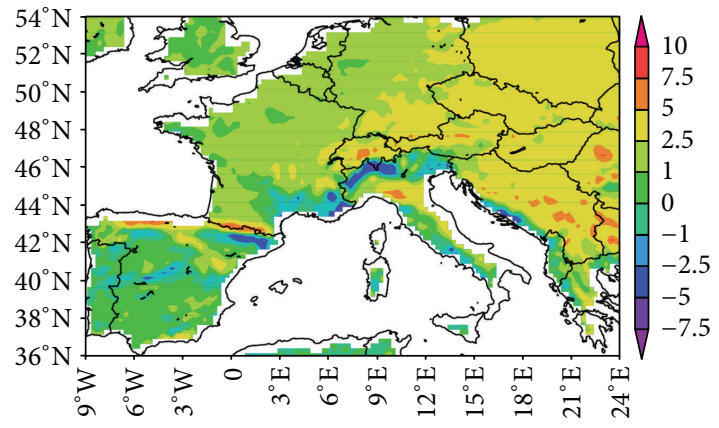

(b) Winter (DJF) season (model-OBS)

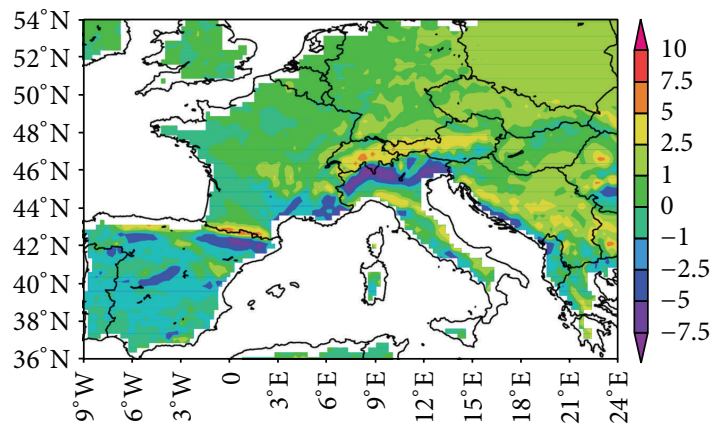

(d) Spring (MAM) season (model-OBS)

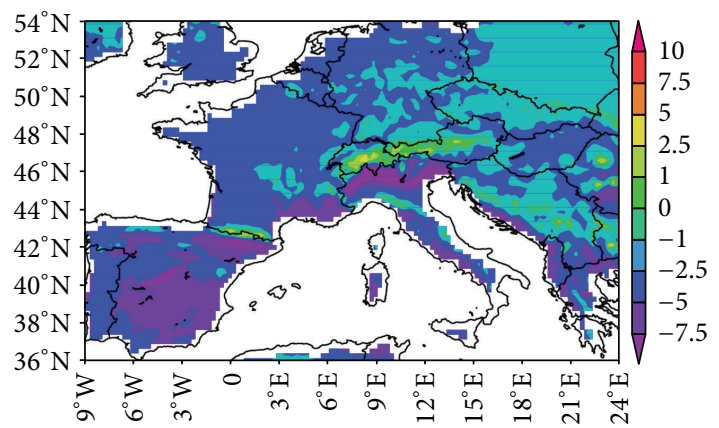

(f) Summer (JJA) season (model-OBS)

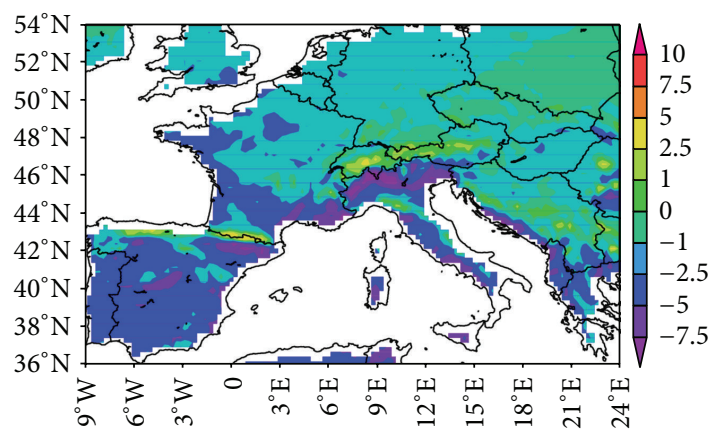

(h) Autumn (SON) season (model-OBS)

FIGURE 7: 60-year mean seasonal minimum temperatures at $2 \mathrm{~m}$ height (left panel from OBS and right panel from model-OBS). (a) and (b) for winter season (DJF); (c) and (d) for spring season (MAM); (e) and (f) for summer season (JJA); and (g) and (h) for autumn season (SON).

which is to be examined further considering the details of surface characteristics.

Figure 7 shows the mean seasonal minimum temperatures over different parts in Europe. Once again the results show warm bias in winter minimum temperatures (Figures $7(\mathrm{a})$ and $7(\mathrm{~b}))$ particularly over Eastern and Central Europe, where the temperatures are simulated about 2 to $5^{\circ} \mathrm{C}$ higher than the observations. In summer the minimum 


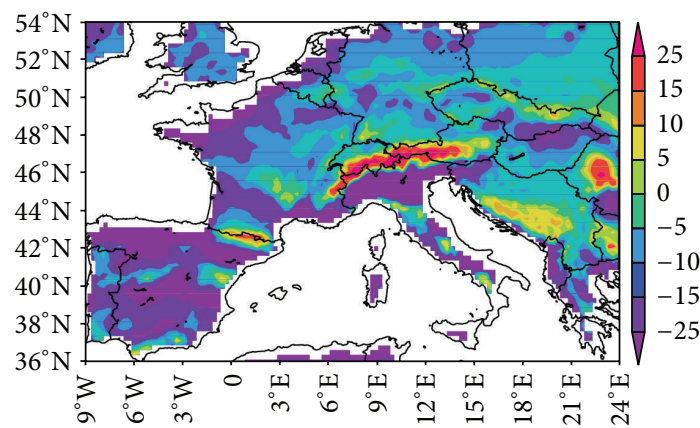

(a) Normalized BIAS for summer maximum temperatures (OBS versus model)

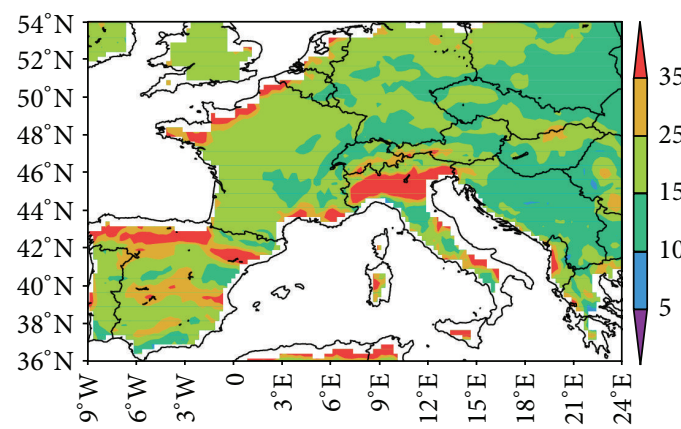

(c) Normalized MAE for summer maximum temperatures (OBS versus model)

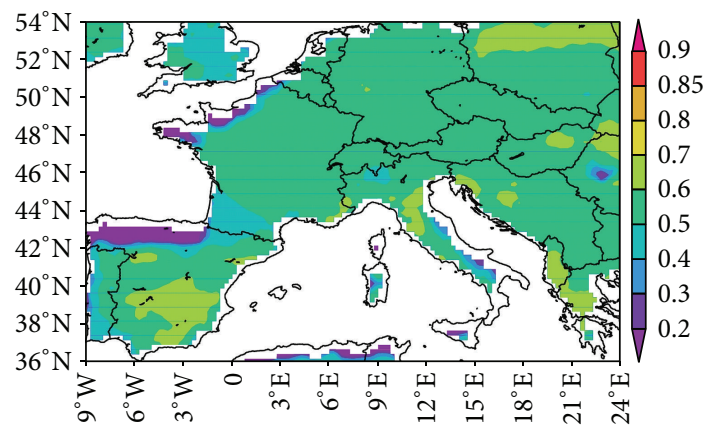

(e) Correlation coefficient for summer maximum temperatures (OBS versus model)

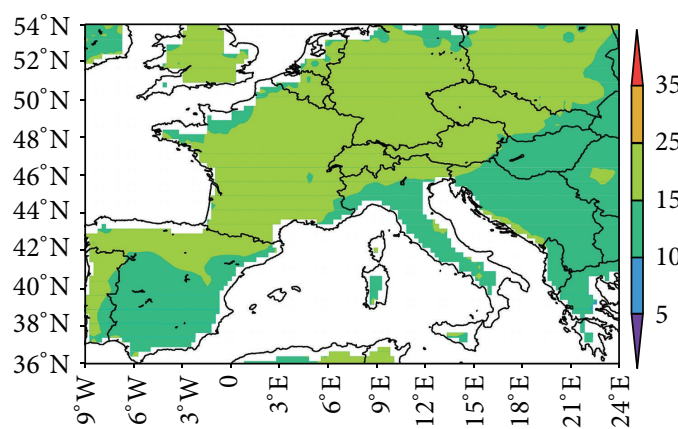

(g) NSTDEV for summer maximum temperatures (OBS versus model)

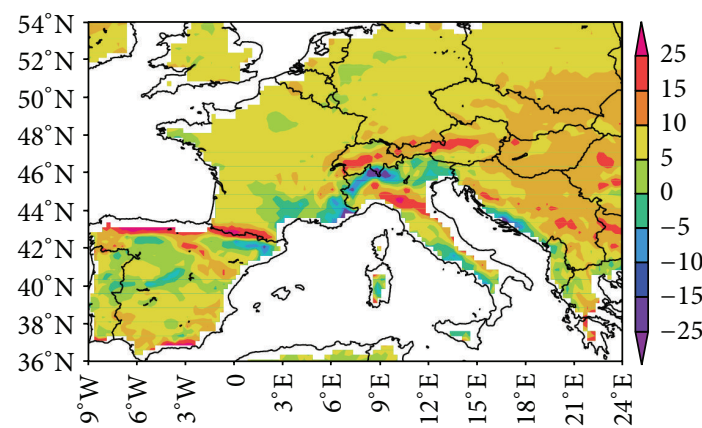

(b) Normalized BIAS for winter minimum temperatures (OBS versus model)

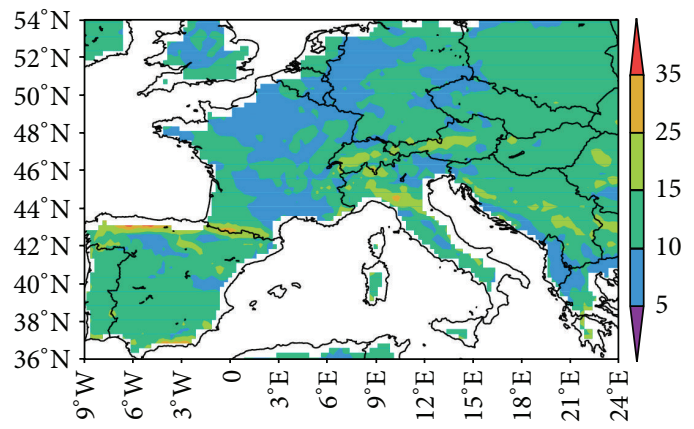

(d) Normalized MAE for winter minimum temperatures (OBS versus model)

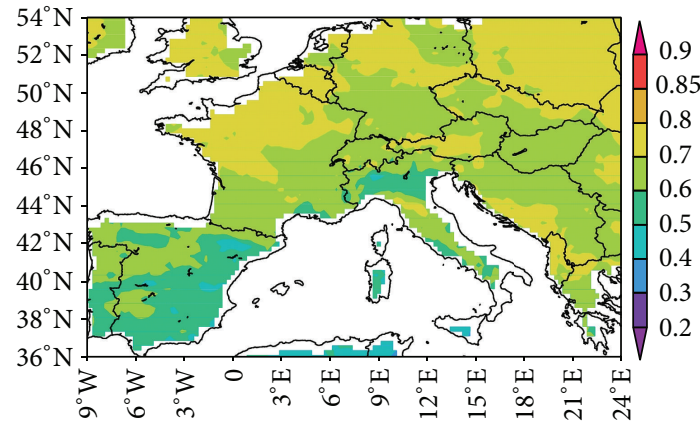

(f) Correlation coefficient for winter minimum temperatures (OBS versus model)

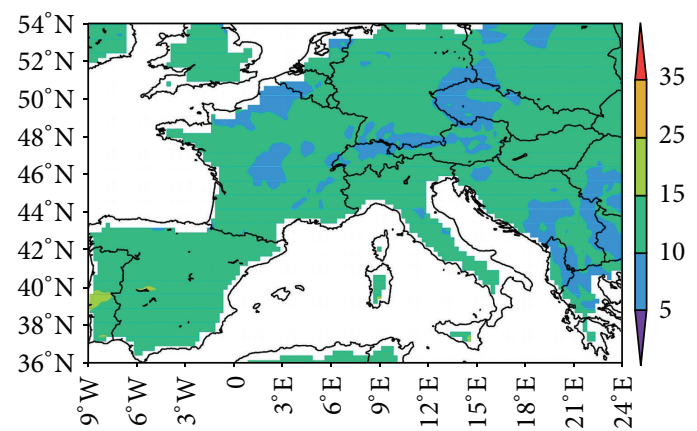

(h) NSTDEV for winter minimum temperatures (OBS versus model)

FIGURE 8: Statistical indices for 60-year summer seasonal maximum temperatures at $2 \mathrm{~m}$ height (left panel). Right panel is the same as left panel but for minimum temperatures in winter seasons from (a) and (b) for normalized BIAS (\%); (c) and (d) for normalized MAE (\%); (e) and (f) correlation coefficient and (g) and (h) are for NSTDEV (\%) between observations and model. 


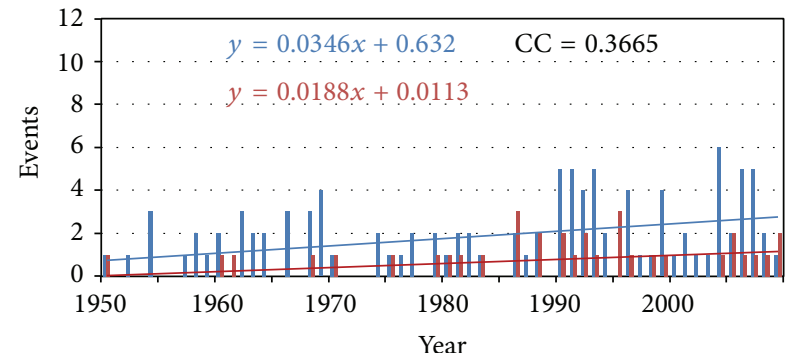

(a) Zone 1

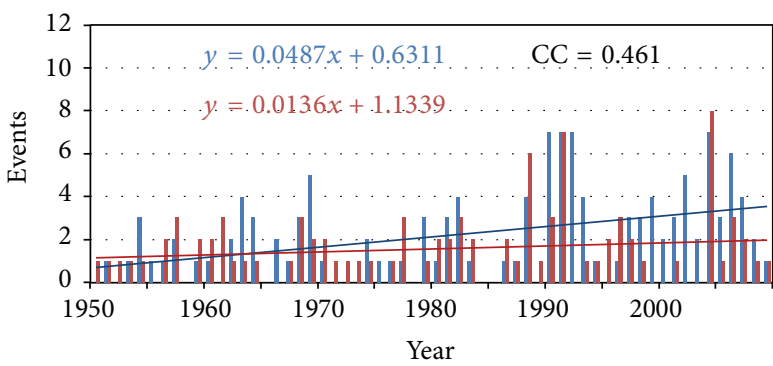

(c) Zone 3

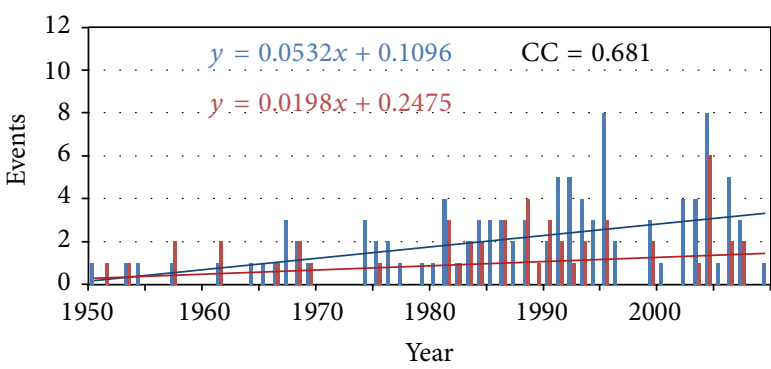

(e) Zone 5

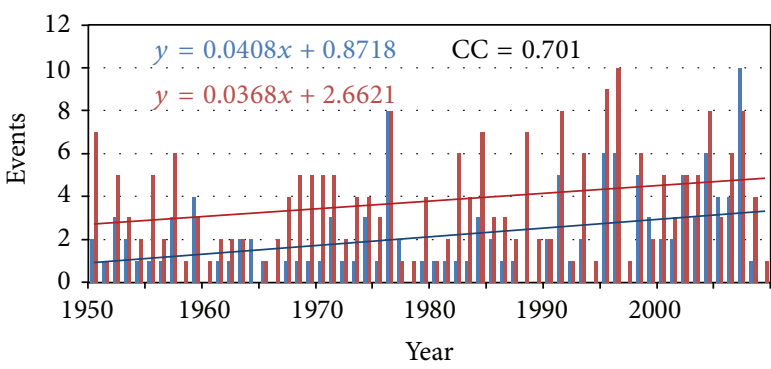

(g) Zone 7

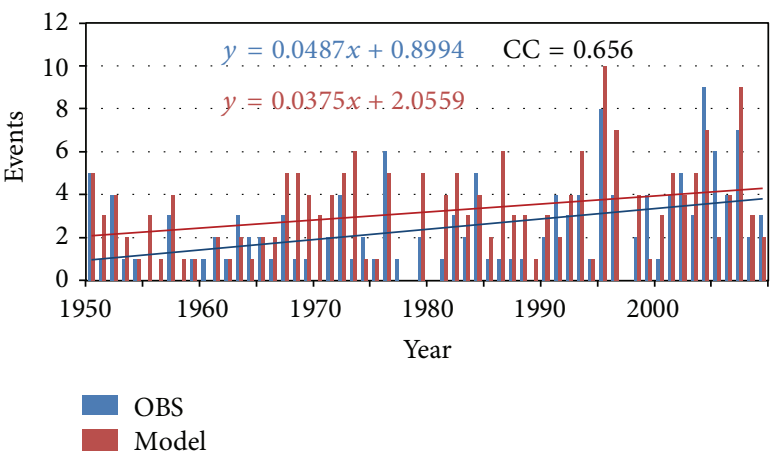

(i) Zone 9

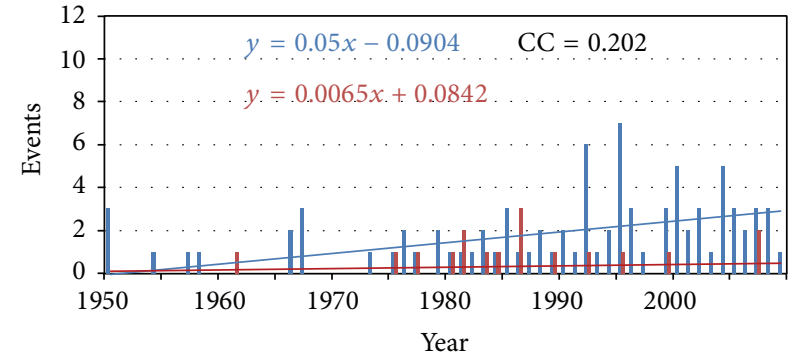

(b) Zone 2

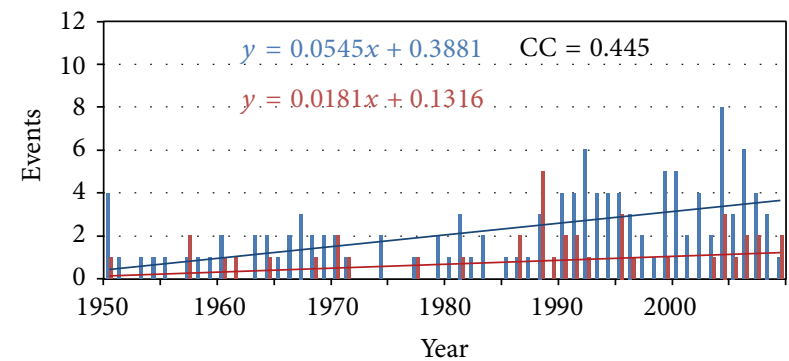

(d) Zone 4

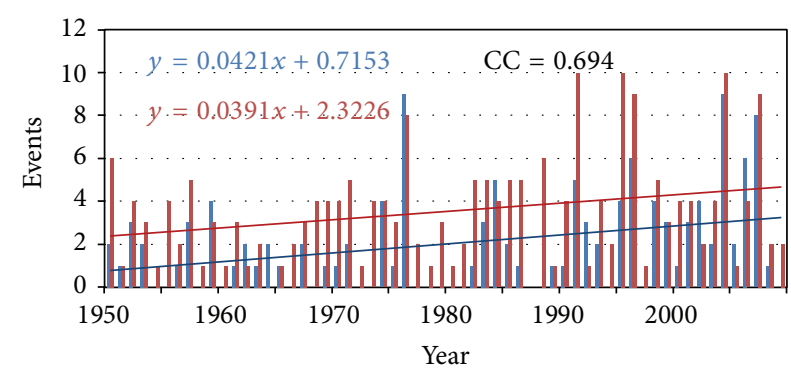

(f) Zone 6

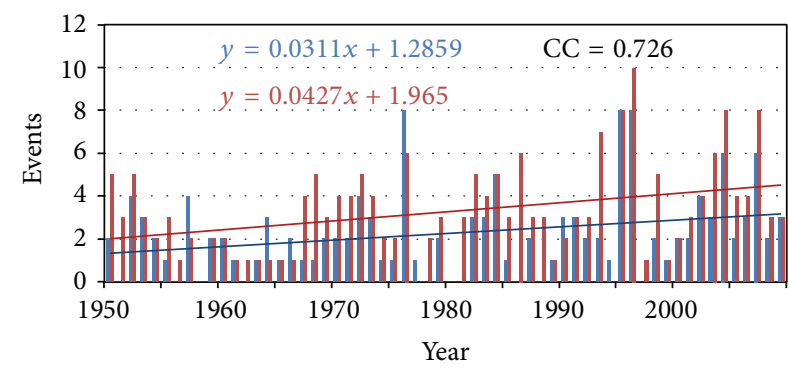

(h) Zone 8

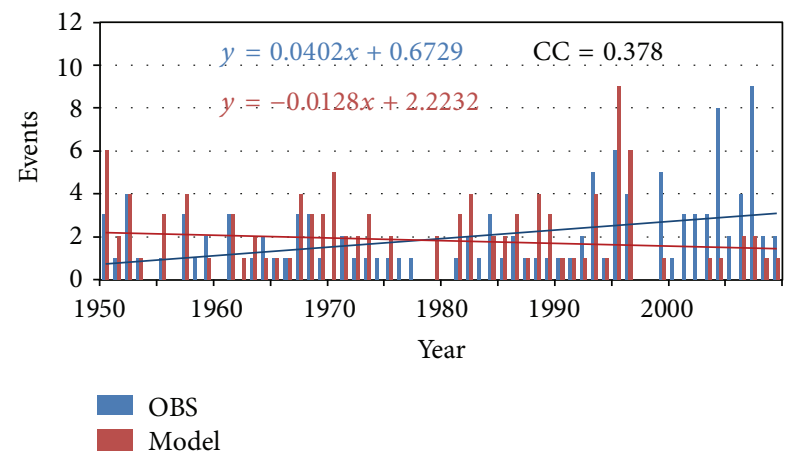

(j) Zone 10

FIgure 9: Continued. 


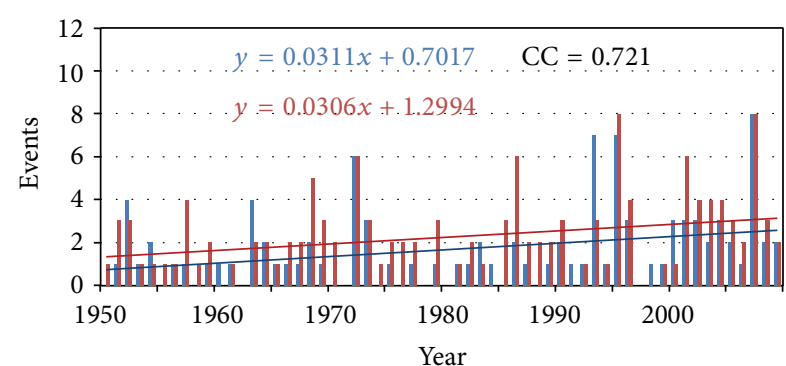

(k) Zone 11

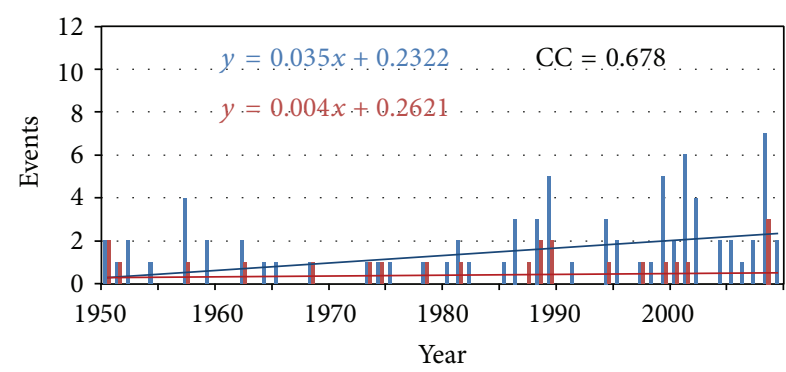

(m) Zone 13

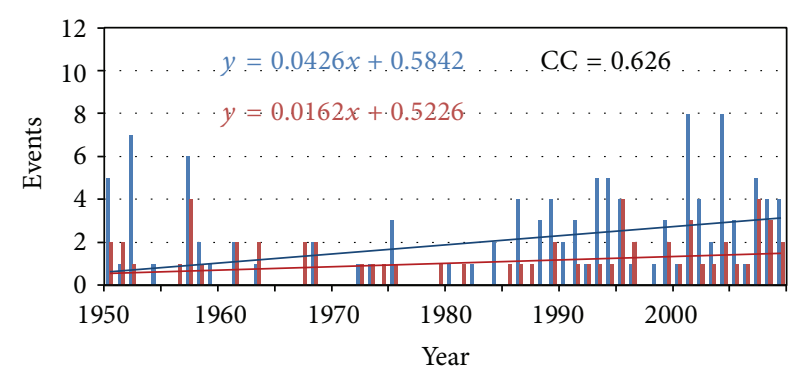

(l) Zone 12

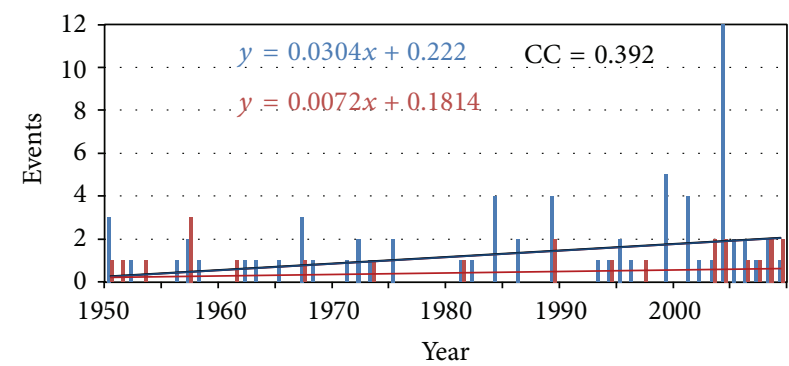

(n) Zone 14

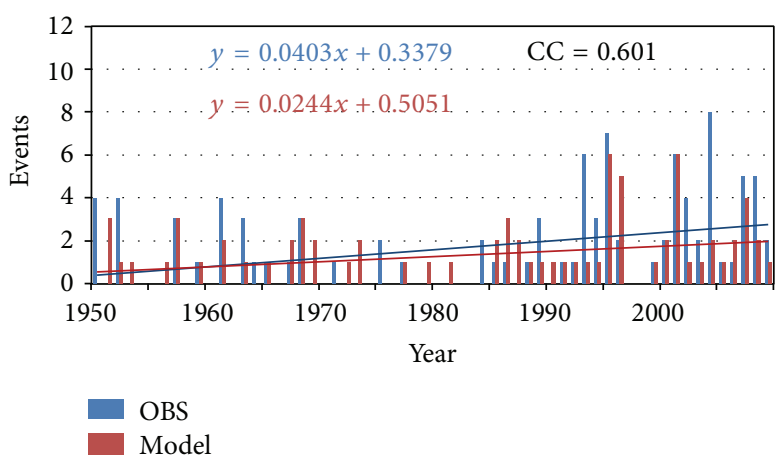

(o) Zone 15

FIGURE 9: Time series for model and observed heat waves for all 15 zones along with their linear trends.

temperatures are simulated by about $5^{\circ} \mathrm{C}$ lower than the observations especially over western and Central Europe indicating a cold bias in summer minimum temperatures (Figures $7(\mathrm{e})$ and $7(\mathrm{f})$ ). In autumn season also there is slight cold bias of -1 to $-2.5^{\circ} \mathrm{C}$ in minimum temperatures over the whole of Europe. In spring season the simulated minimum temperatures fairly agree well with corresponding values from observations (Figures $7(\mathrm{c}), 7(\mathrm{~d}), 7(\mathrm{~g})$, and $7(\mathrm{~h})$ ) in both patterns and with less bias values $\left(-1\right.$ to $\left.1^{\circ} \mathrm{C}\right)$. The above results clearly demonstrate that model performance with respect to maximum temperatures in summer season and minimum temperatures in winter seasons is relatively poor as compared to the other two seasons. To quantify the errors, we computed different statistical indices NBIAS, NMAE, CC, and NSDEV for daily maximum temperatures in summer seasons and daily minimum temperatures in winter seasons. Figure 8 shows the NBIAS, NMAE, CC, and NSDEV. The results indicate that for summer maximum temperatures the NBIAS (Figure $8(\mathrm{a})$ ) is about $-25 \%$ in Iberian region, $-15 \%$ to $15 \%$ in western, central, and eastern parts of Europe, and about $15 \%$ to $25 \%$ over Alps and a few areas in eastern Europe. This indicates underestimation of summer temperatures in Iberian Peninsula and parts of western, central, and Eastern Europe and overestimation over Alps and other parts in Western Europe. The model in general produces a positive temperature bias during winter seasons over most parts of Europe ( 0 to $15 \%$ ) with a higher positive bias (>15\%) over Alps, coast line in Iberian Peninsula, central parts, Italy, and parts in western Europe. The above results indicate a warm bias in simulating winter minimum temperatures over almost the whole of Europe. Spatial error statistics clearly show the model performance is relatively poor over Iberia than the rest of Europe. The spatial distribution of NMAE confirms the poor performance of the model for winter minimum temperatures over Iberia, which is about $25 \%$ in Iberian region (Figures 8(c) and 8(d)) and less (10\% to $15 \%)$ over Central and Eastern Europe. The NMAE in winter minimum temperatures is lower by $10 \%$ in all areas than the corresponding values for summer maximum temperatures indicating less bias in winter temperatures relative to summer. 
TABLE 2: Observed and modeled total number of heat and cold waves during the period 1950-2009, 1950-1970, and 1971-2009.

\begin{tabular}{|c|c|c|c|c|c|c|c|c|c|c|c|c|}
\hline \multirow{3}{*}{ Zones } & \multicolumn{6}{|c|}{ Heat waves } & \multicolumn{6}{|c|}{ Cold waves } \\
\hline & \multicolumn{2}{|c|}{ 1950-2009 } & \multicolumn{2}{|c|}{$1950-1970$} & \multicolumn{2}{|c|}{ 1971-2009 } & \multicolumn{2}{|c|}{ 1950-2009 } & \multicolumn{2}{|c|}{$1950-1970$} & \multicolumn{2}{|c|}{ 1971-2009 } \\
\hline & OBS & MOD & OBS & MOD & OBS & MOD & OBS & MOD & OBS & MOD & OBS & MOD \\
\hline 1 & 105 & 35 & 29 & 5 & 77 & 31 & 27 & 27 & 0 & 8 & 27 & 19 \\
\hline 2 & 86 & 17 & 11 & 1 & 75 & 16 & 59 & 17 & 18 & 5 & 41 & 12 \\
\hline 3 & 127 & 93 & 32 & 28 & 96 & 67 & 50 & 18 & 18 & 6 & 32 & 12 \\
\hline 4 & 123 & 41 & 29 & 9 & 96 & 34 & 47 & 33 & 15 & 12 & 32 & 21 \\
\hline 5 & 104 & 51 & 14 & 10 & 90 & 41 & 36 & 15 & 13 & 7 & 23 & 8 \\
\hline 6 & 120 & 211 & 27 & 55 & 94 & 160 & 97 & 63 & 25 & 9 & 72 & 54 \\
\hline 7 & 127 & 227 & 29 & 64 & 99 & 168 & 110 & 59 & 30 & 13 & 80 & 46 \\
\hline 8 & 134 & 196 & 34 & 50 & 102 & 150 & 138 & 55 & 33 & 11 & 105 & 44 \\
\hline 9 & 143 & 192 & 33 & 52 & 110 & 143 & 107 & 57 & 23 & 12 & 84 & 45 \\
\hline 10 & 114 & 110 & 31 & 45 & 83 & 70 & 87 & 31 & 16 & 9 & 71 & 22 \\
\hline 11 & 99 & 134 & 25 & 38 & 74 & 98 & 165 & 82 & 30 & 20 & 135 & 62 \\
\hline 12 & 113 & 61 & 28 & 19 & 85 & 42 & 109 & 49 & 37 & 13 & 72 & 36 \\
\hline 13 & 78 & 23 & 17 & 6 & 61 & 17 & 99 & 68 & 48 & 34 & 51 & 34 \\
\hline 14 & 69 & 24 & 15 & 8 & 54 & 16 & 46 & 23 & 24 & 13 & 22 & 10 \\
\hline 15 & 94 & 75 & 25 & 21 & 69 & 54 & 79 & 47 & 18 & 12 & 61 & 35 \\
\hline
\end{tabular}

Spatial correlations for summer and winter temperatures are computed at $95 \%$ significance level and are presented in Figures 8(e) and 8(f). Spatial correlation distribution (Figures $8(\mathrm{e})$ and $8(\mathrm{f}))$ shows high correlations $(>0.6)$ for winter indicating better simulation of winter minimum temperatures than the summer temperatures. In both the cases relatively poor correlations are found along the coastline of Iberia and a few isolated areas in Western Europe and Italy. Further the spatial NSTDEV (Figures $8(\mathrm{~g})$ and $8(\mathrm{~h})$ ) distributions indicate higher model versus observation scatter (15-25) in summer as compared to the winter (5 to 10 ). The error statistics (Figures $8(\mathrm{~g})$ and $8(\mathrm{~h})$ ) indicate that the model performance is poor over Iberian and Mediterranean regions relative to central and Eastern Europe. Overall, WRF-ARW model produces relatively better temperature simulation in the 60-year period in spring and autumn seasons than in summer and winter which is perhaps related to the representation of the land surface energy balance and the choice of surface physics used in the model. In general the model gives a cold bias in summer and warm bias in winter and the model performance is relatively better in Central and Eastern Europe than in Iberian region. Garcia-Diez et al. [63] have reported that the WRF model mean bias in temperature simulation significantly depends on the season, and warm bias in winter and cold bias in summer were simulated over Europe. Our present results corroborate their findings on a seasonal scale.

4.3. Extreme Heat and Cold Wave Occurrences. Here, the changes in extreme weather events associated with heat waves in summers and cold waves in winters over different zones in Europe are presented. The model domain is divided into 15 zones based on topography (Figure 1). The frequency of heat waves is derived from daily maximum temperatures in summers and that of cold waves from the daily minimum temperatures in winter seasons. Occurrence of heat wave condition is defined from the number of instances with maximum temperature exceeding $5^{\circ} \mathrm{C}$ of its long-term mean [61] consecutively over more than 3 days or more. Here the long-term mean for summer maximum and winter minimum is computed from maximum daily temperatures for 60-year summer months and minimum daily temperatures for 60 year winter months, respectively. Similarly occurrence of cold wave condition is defined from the number of instances with minimum temperature falling below $5^{\circ} \mathrm{C}$ of its long-term mean consecutively over 3 days or more. Daily minimum winter temperatures for the 60-year period are used with deviation below $5^{\circ} \mathrm{C}$ of its mean to identify the cold waves over 60-year period.

Using the above criteria, we computed area averaged daily maximum temperatures from observations and model. The number of heat waves for each year in summer season is computed and presented in Figure 9. Similarly area averaged daily minimum temperatures are computed for all 60-year winter seasons and for each winter season the number of cold wave events is identified (Figure 10). Linear curve fitting is made and trend line between observed and modeled values of heat/cold waves are plotted to assess the trends in extreme temperature events.

It is seen that the number of simulated heat waves in most zones increases with time and the model simulated trends are consistent with the increasing trends found in observations except in zones $2,10,12,13$, and 14 . It is noted that the number of heat wave (frequency) increases significantly in Central Europe especially in zones 6, 7, 8, 9, and 11, where the model produced more numbers of heat waves than the observed. Over zones 1 to 4 in Iberia, observations indicate significantly increasing number of heat waves in contrast to the model generated heat waves. The underrepresentation 


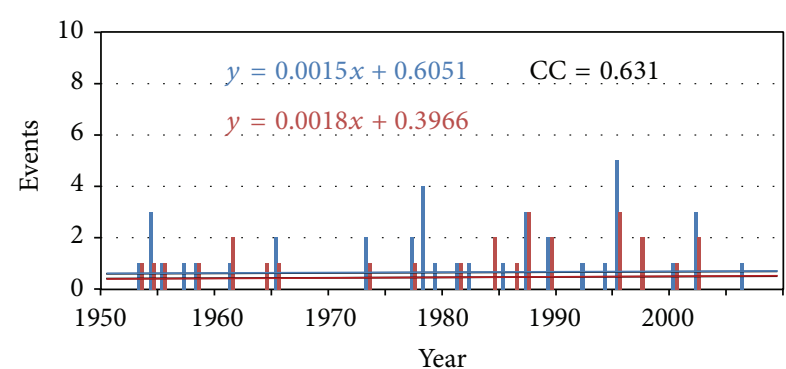

(a) Zone 1

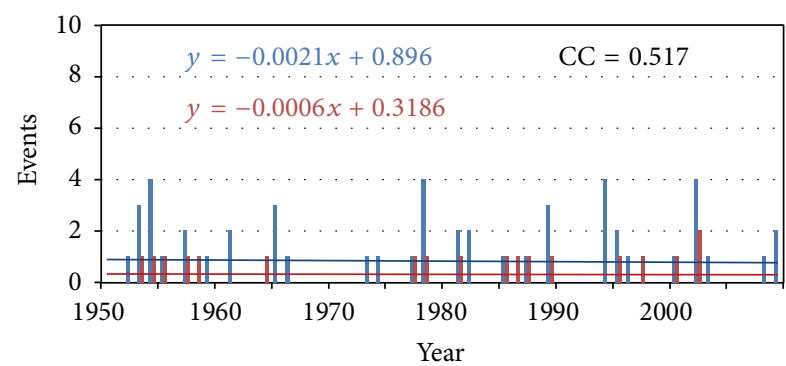

(c) Zone 3

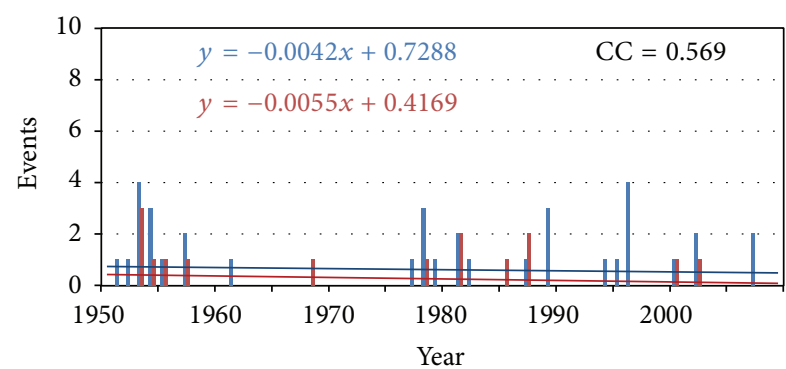

(e) Zone 5

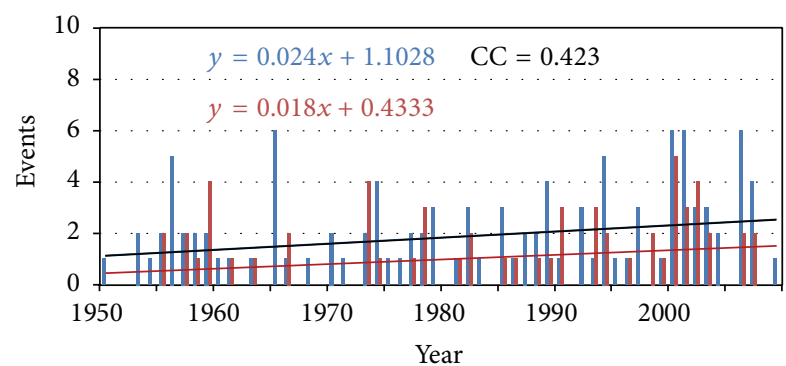

(g) Zone 7

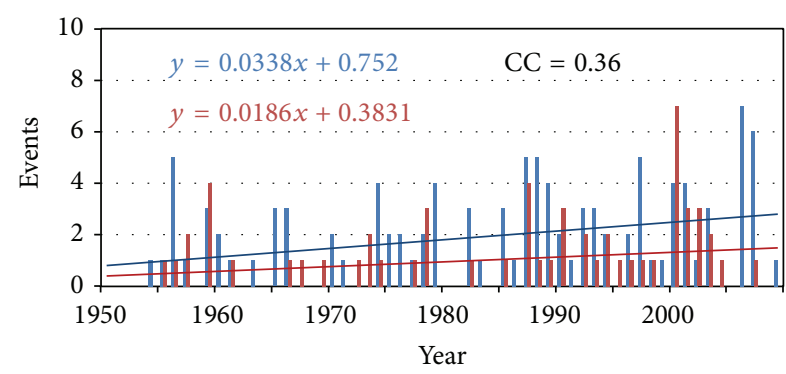

OBS

Model

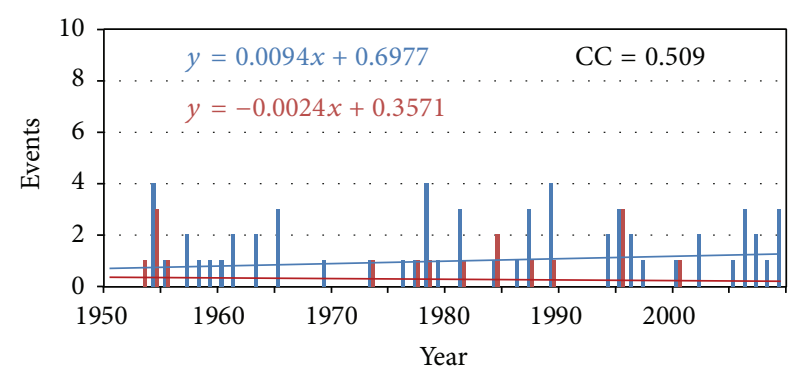

(b) Zone 2

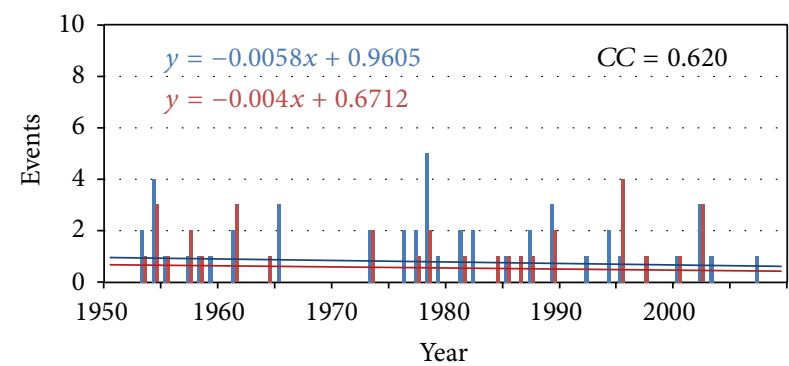

(d) Zone 4

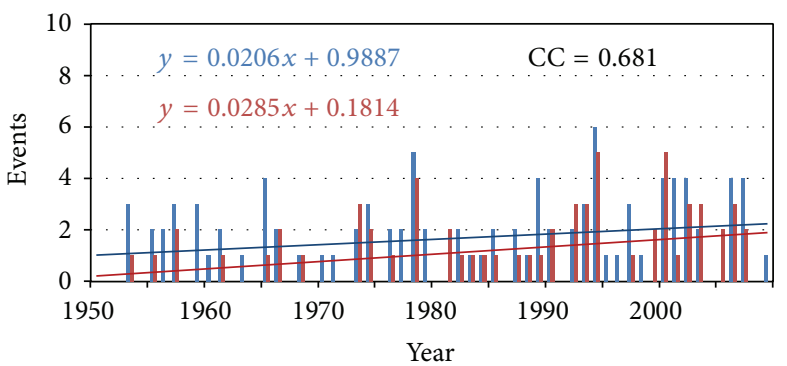

(f) Zone 6

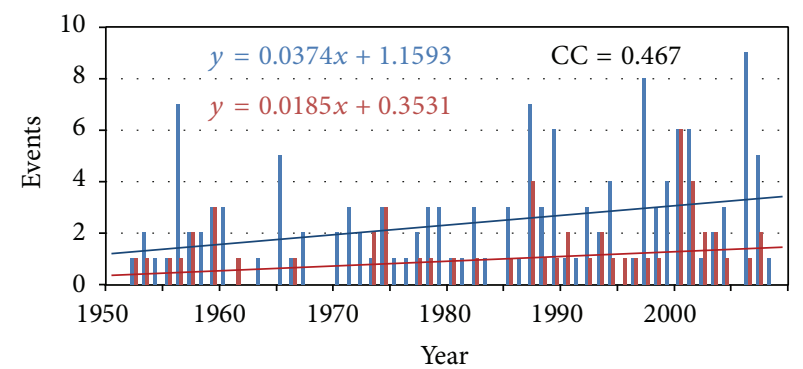

(h) Zone 8

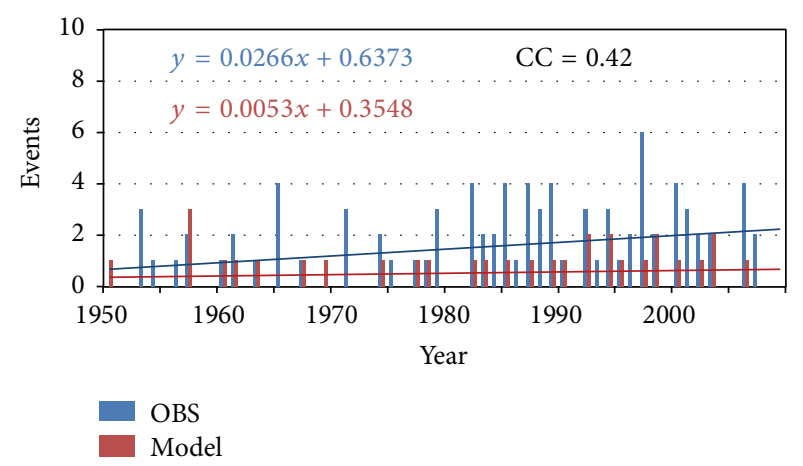

(j) Zone 10

FIgURE 10: Continued. 


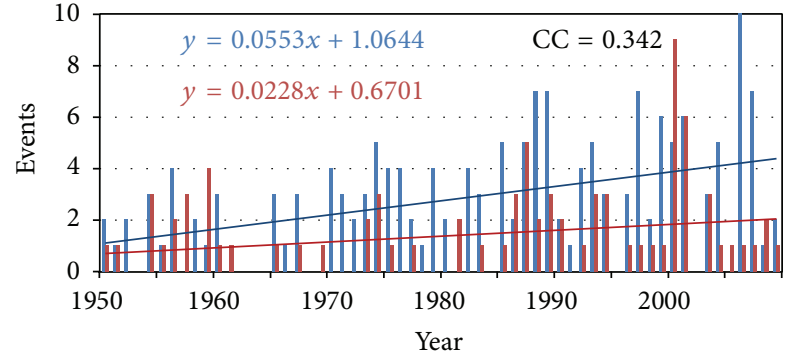

(k) Zone 11

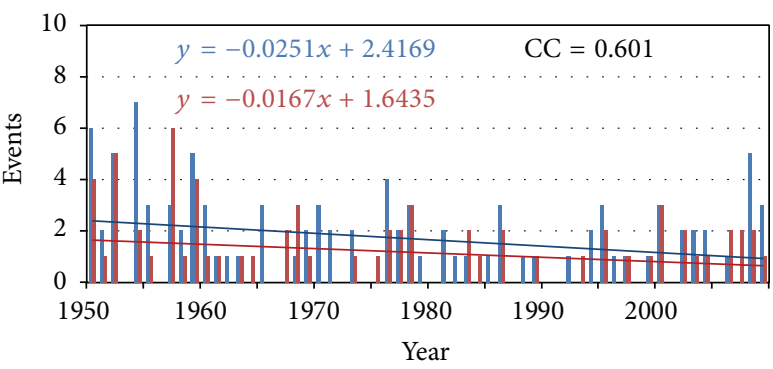

(m) Zone 13

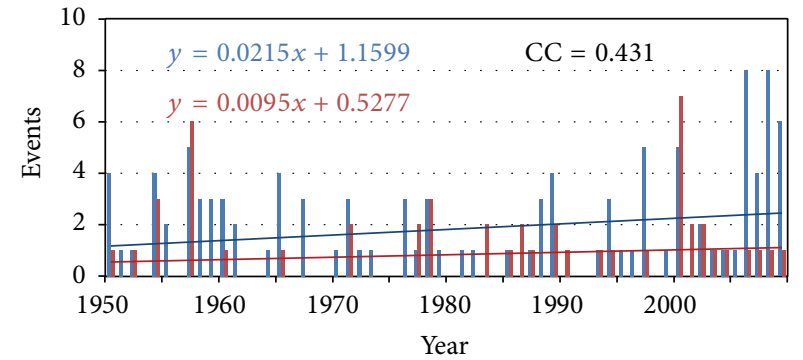

(l) Zone 12

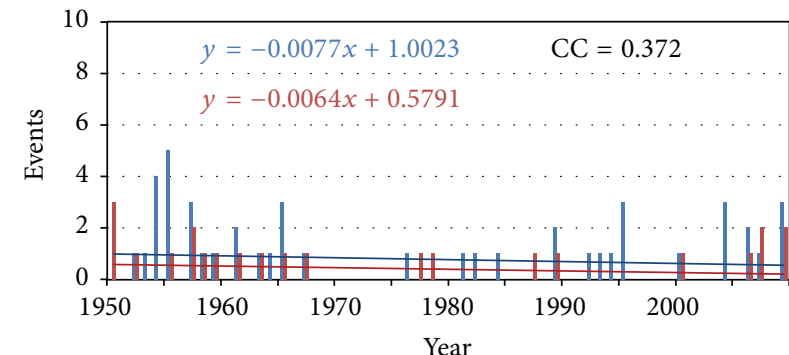

(n) Zone 14

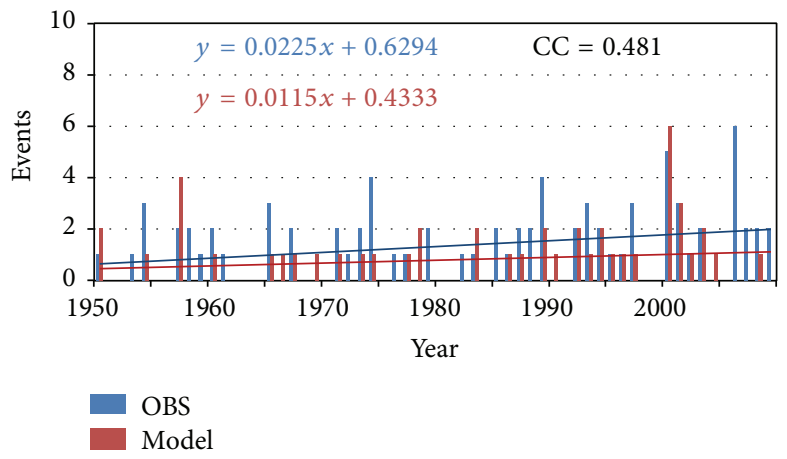

(o) Zone 15

Figure 10: Time series for model and observed cold waves for all 15 zones along with their linear trends.

in number of heat waves in zones $1-4$ is consistent with the results obtained in the previous sections, where it was shown that the model exhibits a cold bias in simulating summer maximum temperatures over Iberian region and a few other parts. The correlations between model generated and observed heat waves for each zone are computed and presented in Figure 9 over each zone panel. Clearly the model simulated good trends of heat wave simulation in most zones with remarkably high correlations $(>0.6)$ except in zones $1-4$, 10 , and 14 where poor correlations of $0.22-0.45$ are obtained. Similarly, the model simulated increasing number of cold waves in Central Europe and some parts of Eastern Europe in zones 6 to 12 in agreement with observations (Figure 10). Over Iberia (zones 1 to 5) no significant trend in cold waves is found. In zones 3-5, 13, and 14, located over Mediterranean region, a decreasing trend in cold waves is simulated as also found in observations though the trend is not very significant. Moderate correlations $(\sim 0.34)$ in zone 11 and high correlations $(0.68)$ in zone 6 are found for cold waves (Figure 10). In zone 2 located in Iberia (Figure 10) there is a decreasing trend of cold waves in WRF while an increasing trend is noticed in observed ones. The number of heat waves and cold waves simulated and observed in different zones is presented in Table 2. An increase in the number of heat waves is noticed in all the zones during the period 19702010 (Table 2) in both simulation and observations. More than $80 \%$ of the total number of heat waves occurred during the period 1970-2010 in both observations and simulation. The incidence of heat waves as well as cold waves has been found to be highest in zones 6-12 followed by zones 15, 1, 4 , and 3 . In the remaining zones the heat and cold wave occurrence is not very significant. Thus the above analysis of frequency of heat waves and cold waves shows that both Central Europe and some parts of Eastern Europe are highly vulnerable to both heat waves and cold waves as significant linear increase is seen in the respective areas. The increasing trends in heat and cold wave events are well captured by model in agreement with observed extreme events. The most striking aspect is the inability of the model in simulating the heat waves in the Iberian region. In Iberia the model 


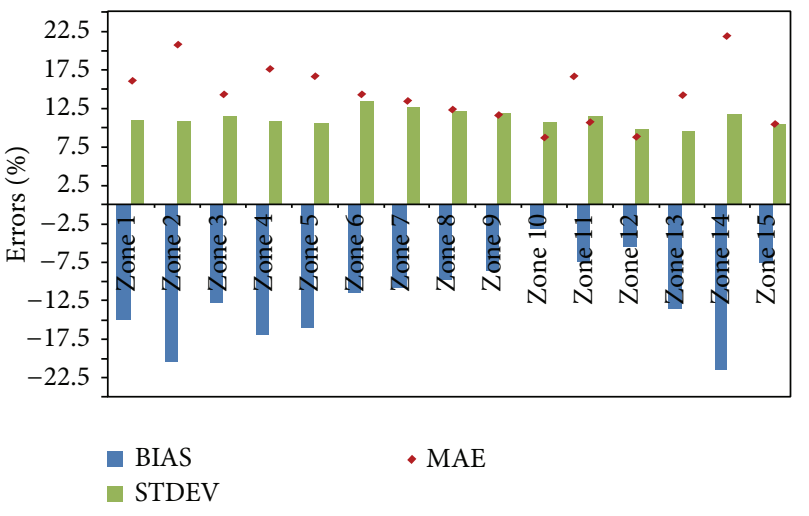

(a) Maximum temperatures in summer

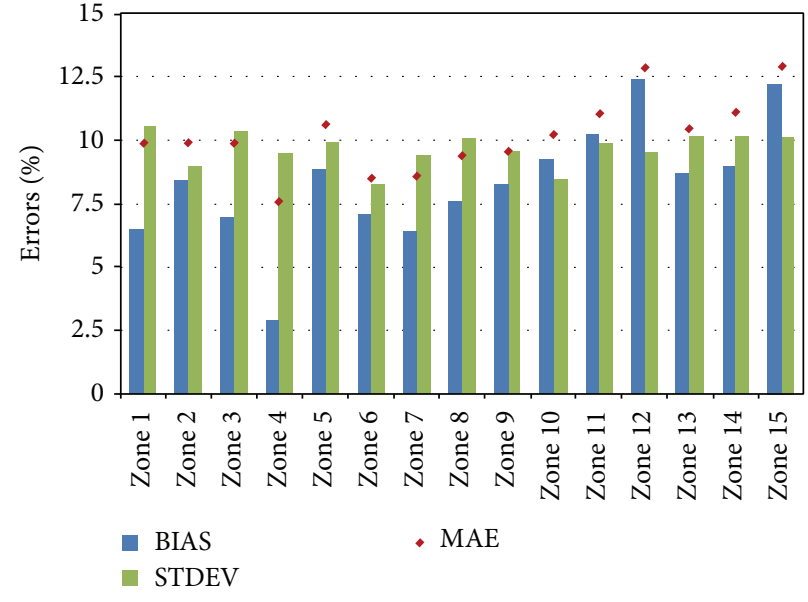

(b) Minimum temperatures in winter seasons

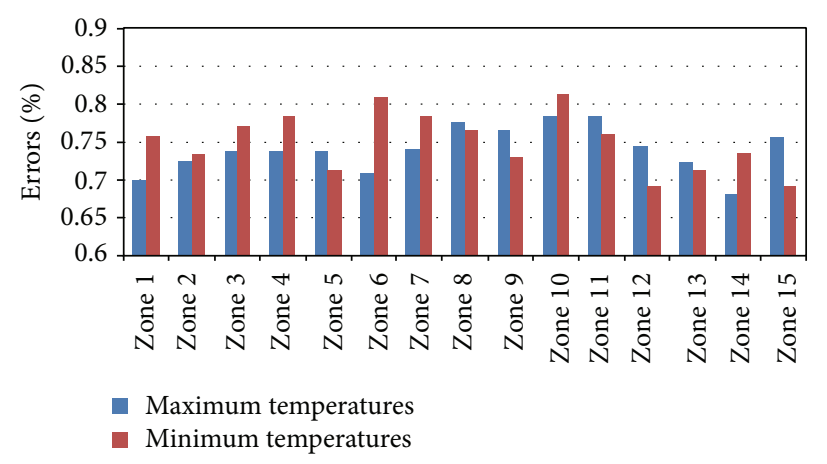

(c) Correlation coefficient

FIGURE 11: Statistical indices (NBIAS, NSTDEV, and NMAE) between model and observed (a) maximum temperatures in summer, (b) minimum temperatures in winters and (c) correlation between model and observed maximum and minimum temperatures for each zone.

performed slightly better in cold waves simulation in terms of a high CC in zones 1 and 4 for the cold waves and the CC in the zones 1-4 are higher for cold waves than for heat waves. It is also noted that the cold waves in Mediterranean region are in decreasing trend though with less significance.

To examine the spatial variation of extreme heat and cold waves we analysed the daily maximum and minimum temperatures for summer and winter seasons averaged over different zones from observations and model. The statistical metrics NBIAS, NSTDEV, NMAE, and CC computed between simulations and observations for maximum and minimum temperatures are computed and presented in Figure 11. As already noted, the model underestimated summer maximum temperatures indicating cold bias in all zones with an error of -2.5 to $-22.5 \%$. The errors are less in Central Europe, that is, from zones 6-13 and they are more (about $22.5 \%$ ) in Iberian region. The same pattern is also noticed in NMAE. The NSTDEV indicates large scatter of the errors in the range of $10 \%$ to $12.5 \%$ and almost all zones exhibit similar scatter. Daily maximum temperatures for all 60 -year summer seasons have correlations $(>0.65)$, in that zone 11 has a maximum correlation of 0.79 followed by 0.78 in zone 10. For the minimum temperatures the NBIAS in different zones is in the range of $+2.5 \%$ to $+12.5 \%$ which indicates a warm bias in all zones but the errors are lower in winter minimum temperatures than those in summer maximum temperatures. Zone 12 has the maximum warm bias followed by zones 15 and 11. In the remaining zones the errors are more or less similar and in zone 4 the errors are relatively low (about 2.5\%). The NMAE and NSDEV in all zones are in the range of $7.5 \%$ to $12.5 \%$ and maximum NMAE and NSDEV are found in zone 11 followed by zone 15 . The correlations for winter temperatures are improved (0.69-0.82) over summer maximum temperatures. The highest correlation $(0.82)$ is noted in zone 10 , followed by zone 6 with 0.81 .

4.4. Long-Term Temperature Trends. To examine how the model reproduced the long temperature trends in the study domain, we have made a time series analysis of spatial mean temperatures over (i) Iberian Peninsula, (ii) Central Europe, and (iii) Eastern Europe from values derived from model and those from observations (Figure 12). From this Figure it is evident that the deviations between observations and model values both in the seasonal maximum mean as well as minimum mean values are high over Iberian Peninsula relative to Eastern and Central Europe regions. A simple linear trend analysis is performed to examine the temperature trends. This 

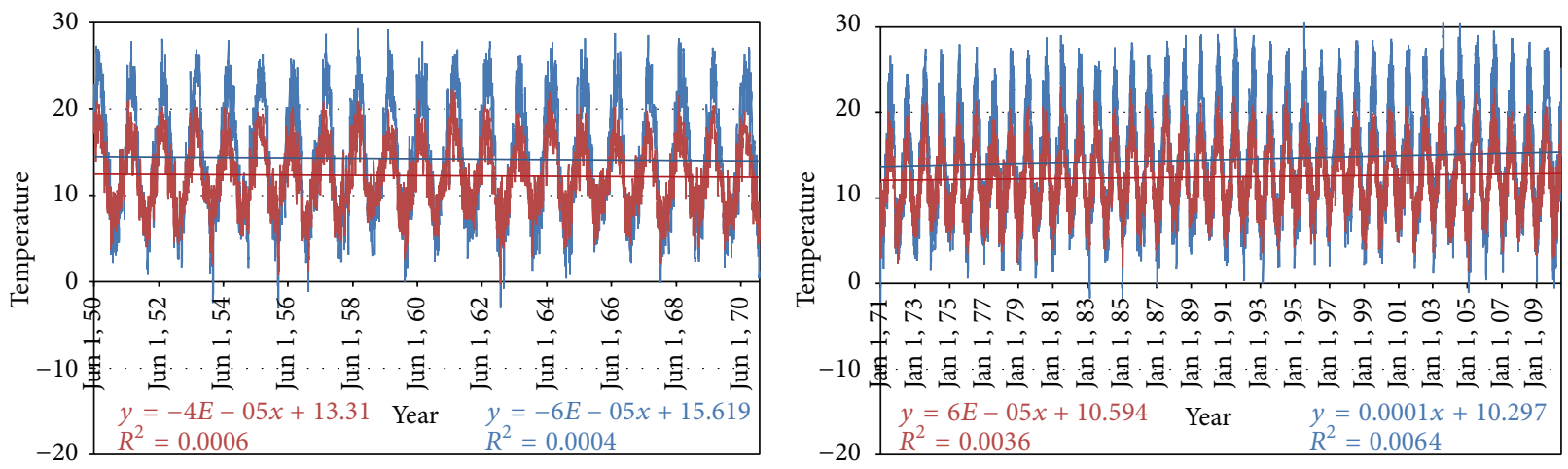

(a)
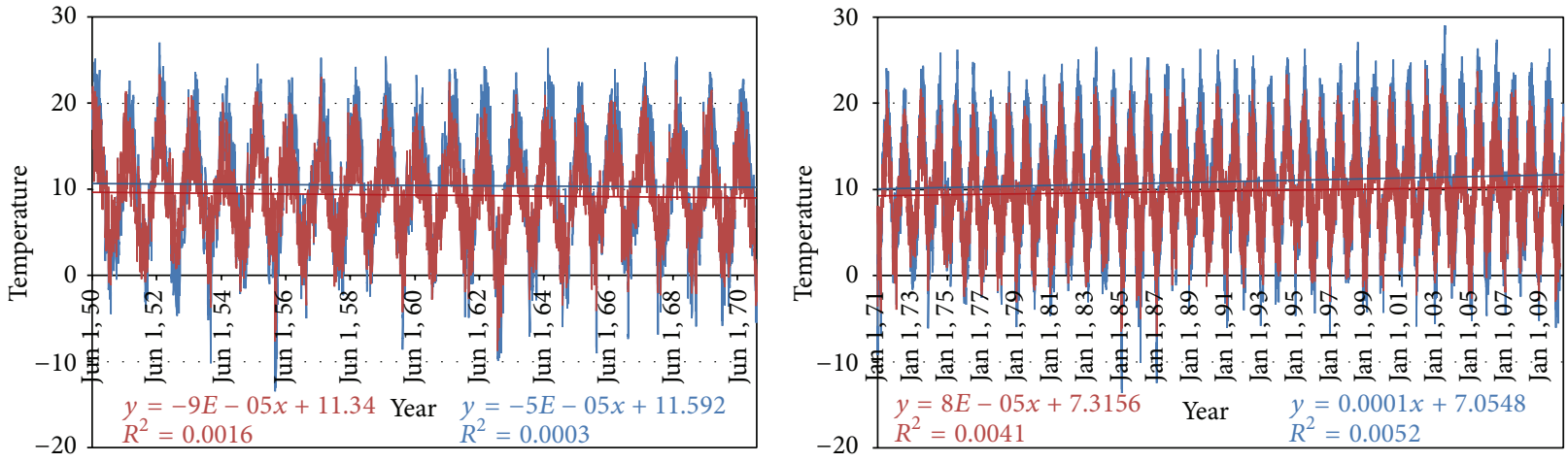

(b)
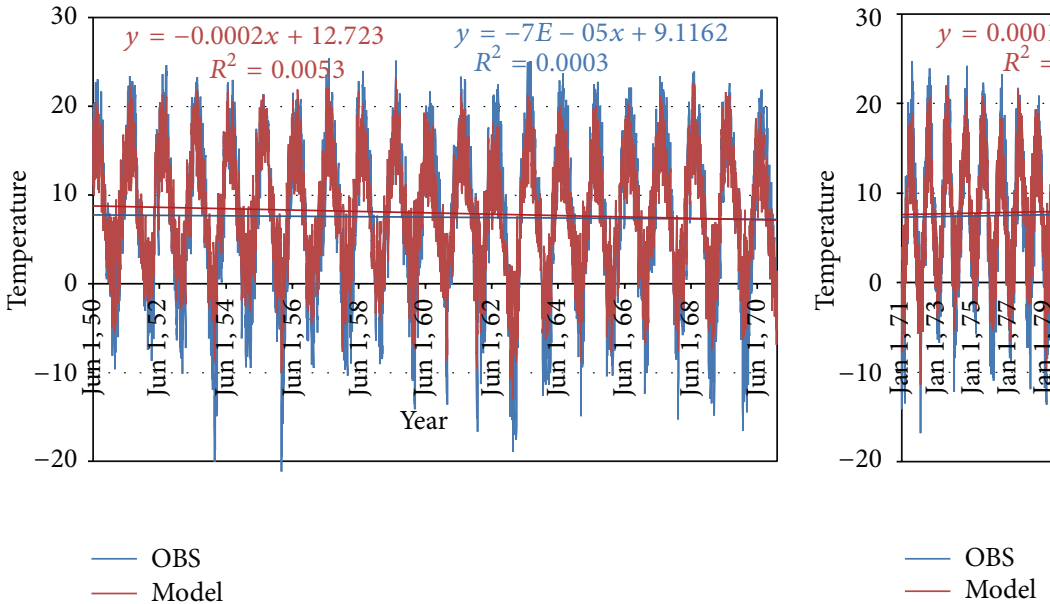

(c)

Figure 12: Time series of model and observed daily mean temperatures (left panel is for the period of 1950-1970 and right panel is for 1971-2010) averaged over (a) Iberia, (b) Central Europe, and (c) Eastern Europe regions.

has already been noted in the spatial distribution of seasonal temperatures discussed above. In all the three regions there is a very small decreasing trend in mean temperatures in the period from 1950 to 1970 and a very small increasing trend in mean temperatures in the period from 1970 to 2010 though the variation is not very significant. Except for the Iberian Peninsula region the model is able to reproduce the peaks of temperature quite well throughout the period 1950-2010 in the rest of Europe. The trends in simulated temperature are noted to agree very well with observed temperatures.

\section{Summary and Conclusion}

A long-term regional climate simulation is performed over Europe using the WRF-ARW regional climate model by downscaling the NCEP reanalysis data at a $25 \mathrm{~km}$ model horizontal resolution. The model simulated mean, maximum, minimum, seasonal mean, maximum, and minimum temperatures are analysed by comparisons with corresponding data derived from E-OBS analysis data sets over the study domain. A comparison of the spatial patterns of the above 
parameters between simulations and observations indicated that the model generally reproduced the temperature patterns over most parts of Europe except Iberian Peninsula and Mediterranean region, coast lines in Eastern Europe, and Alps in Central Europe. It is required to include the snow and hydrology processes in the land surface physics to properly simulate the surface albedo and the surface energy partitioning for accurately simulating the surface air temperature. In the present study the multilayer soil scheme does not deal with the dynamic snow and soil hydrology aspects. The poor performance of the model over Iberia and Mediterranean region could be partly due to the above deficiencies. Qualitative and quantitative analysis of simulated and observed temperatures clearly indicated a cold bias in summer maximum temperatures, a warm bias in winter minimum temperatures, and a cold bias in mean temperature in the simulations. Seasonal temperature patterns for summer and winter are relatively poor as compared to autumn and spring seasons. The slight poor performance of the model for summer and winter temperatures is probably related to the deficiencies in model surface physics and the surface data sets used as boundary conditions which need to be examined further. The long-term mean temperature analysis indicates that the model could reproduce a small fall in temperatures from 1950 to 1970 and a small rise in temperatures from 1970 to 2010. These trends in longterm temperature are in agreement with trends in observed temperatures in the three distinct regions (Iberian region, Central Europe, and Eastern Europe). The model in general could reproduce the cold and heat wave conditions during the climate period 1950-2010 in agreement with observations, though the trends are poor over the Iberian Peninsula. The study demonstrates that WRF-ARW at $25 \mathrm{~km}$ resolution could reproduce many salient features of regional climate over Europe including the seasonal variations, heat, and cold wave conditions as well as the long-term temperature fluctuations over Europe. The relatively poor performance of the model for summer and winter temperatures could be due to inadequacies of model in capturing the temperature cycle properly over different topographic conditions using the simple soil physics and a sensitivity study is proposed in future study to address this issue with more advanced land surface physics, improved boundary conditions, and accurate terrain information. The multilayer soil model used in the current study simulates the evolution of soil temperatures while the soil moisture, vegetation, canopy, and ice effects are treated from seasonally varying land cover and not explicitly computed. For example, soil hydrological processes become important during summer rainfall or winter snowfall, which requires a soil hydrology model and plant canopy model to realistically account the processes of water storage, evaporation/evapotranspiration, runoff, and their influence on the latent/sensible surface heat fluxes which in turn influence the air temperatures. These processes become important in simulating the long-term climate simulations at regional scale where the land-water effects along coast lines, regional vegetation, and topography are dominant processes. Given these limitations, the present study demonstrates the potential of the ARW model for regional climate studies. The impact of the land surface processes in long-term regional climate simulations will be examined in future studies.

\section{Conflict of Interests}

The authors declare that there is no conflict of interests regarding the publication of this paper.

\section{Acknowledgments}

The authors acknowledge the funding provided by the Geophysics Centre, University of Evora, Portugal, under the Contract with FCT (the Portuguese Science and Technology Foundation), PEst-OE/CTE/UI0078/2011. The authors gratefully acknowledge the NCAR, USA, for the public access of WRF-ARW mesoscale model and NCEP/NCAR USA for the reanalysis data sets used in the study. Authors acknowledge ENSEMBLES project for the public access of the E-OBS data used in this study. The authors are grateful to the super computational facility CESGA, Galicia Supercomputing Center, Spain (http://www.cesga.es/) for the permission to carry out this research. Authors wish to acknowledge the anonymous reviewers for their technical comments which helped to improve the contents of the paper.

\section{References}

[1] B. Bolin and C. D. Keelin, "Large-scale atmospheric mixing as deduced from seasonal and meridional variations of carbon dioxide," Journal of Geophysical Research, vol. 68, no. 13, pp. 3899-3920, 1963.

[2] G. M. Woodwell, R. H. Whittaker, W. A. Reiners, G. E. Likens, C. C. Delwiche, and D. B. Botkin, "The biota and the world carbon budget,” Science, vol. 199, no. 4325, pp. 141-146, 1978.

[3] J. E. Harries, H. E. Brindley, P. J. Sagoo, and R. J. Bantges, "Increases in greenhouse forcing inferred from the outgoing longwave radiation spectra of the Earth in 1970 and 1997," Nature, vol. 410, pp. 355-357, 2001.

[4] Intergovernmental Panel on Climate Change (IPCC), Climate Change. Volumes 1-3, Third Assessment Report, Intergovernmental Panel on Climate Change, Cambridge University Press, Cambridge, UK, 2001.

[5] Intergovernmental Panel on Climate Change (IPCC), Climate Change 2007: The Physical Science Basis, Working Group I Contribution to the Fourth Assessment Report of the IPCC, Intergovernmental Panel on Climate Change, Cambridge University Press, New York, NY, USA, 2007.

[6] R. E. Benestad, "Climate change scenarios for Northern Europe from multi-model IPCC AR4 climate simulations," Geophysical Research Letters, vol. 32, no. 17, Article ID L17704, pp. 1-3, 2005.

[7] I. Hanssen-Bauer, C. Achberger, R. E. Benestad, D. Chen, and E. J. Førland, "Statistical downscaling of climate scenarios over scandinavia: a review," Climate Research, vol. 29, no. 3, pp. 255268, 2005.

[8] C. Tebaldi, K. Hayhoe, J. M. Arblaster, and G. A. Meehl, “Going to the extremes: an intercomparison of model-simulated historical and future changes in extreme events," Climatic Change, vol. 79, no. 3-4, pp. 185-211, 2006. 
[9] C. Schär, P. L. Vidale, D. Lüthi et al., "The role of increasing temperature variability in European summer heatwaves," Nature, vol. 427, no. 6972, pp. 332-336, 2004.

[10] E. Black, M. Blackburn, G. Harrison, B. J. Hoskins, and J. Methven, "Factors contributing to the summer 2003 European heatwave," Weather, vol. 59, pp. 217-223, 2004.

[11] C. Schär and G. Jendritzky, "Climate change: hot news from summer 2003," Nature, vol. 432, pp. 559-560, 2004.

[12] D. Barriopedro, E. Fisher, J. Luterbacher, R. M. Trigo, and R. García-Herrera, "The hot summer of 2010: redrawing the temperature record map of Europe," Science, vol. 322, pp. 220 224, 2011.

[13] M. Beniston, D. B. Stephenson, O. B. Christensen et al., "Future extreme events in European climate: an exploration of regional climate model projections," Climatic Change, vol. 81, no. 1, pp. 71-95, 2007.

[14] G. C. Leckebusch, B. Koffi, U. Ulbrich, J. G. Pinto, T. Spangehl, and S. Zacharias, "Analysis of frequency and intensity of European winter storm events from a multi-model perspective, at synoptic and regional scales," Climate Research, vol. 31, no. 1, pp. 59-74, 2006.

[15] K. Woth, "North Sea storm surge statistics based on projections in a warmer climate: how important are the driving GCM and the chosen emission scenario?" Geophysical Research Letters, vol. 32, no. 22, Article ID L22708, 2005.

[16] K. Woth, R. Weisse, and H. von Storch, "Dynamical modelling of North Sea storm surge extremes under climate change conditions-an ensemble study," Ocean Dynamics, vol. 56, no. 1, pp. 3-15, 2006.

[17] C. L. Castro, R. A. Pielke Sr., and G. Leoncini, "Assessment of value retained and added using the Regional Atmospheric Modeling System (RAMS)," Journal of Geophysical Research, vol. 110, no. 5, 2005.

[18] C. L. S. Castro, R. A. Pielke, and J. O. Adegoke, "Investigation of the summer climate of the contiguous United States and Mexico using the Regional Atmospheric Modeling System (RAMS). Part I: model climatology (1950-2002)," Journal of Climate, vol. 20, no. 15, pp. 3844-3865, 2007.

[19] C. L. Castro, R. A. Pielke Sr., J. O. Adegoke, S. D. Schubert, and P. J. Pegion, "Investigation of the summer climate of the contiguous United States and Mexico using the Regional Atmospheric Modeling System (RAMS). Part II: model climate variability," Journal of Climate, vol. 20, no. 15, pp. 3866-3887, 2007.

[20] B. Rockel, C. L. Castro, R. A. Pielke Sr., H. von Storch, and G. Leoncini, "Dynamical downscaling: assessment of model system dependent retained and added variability for two different regional climate models," Journal of Geophysical Research D: Atmospheres, vol. 113, no. 21, Article ID D21107, 2008.

[21] M. Rummukainen, State-of-the-art with Regional Climate Models, vol. 1, John Wiley \& Sons, New York, NY, USA, 2010.

[22] F. Giorgi and L. Mearns, "Introduction to special section: regional climate modeling revisited," Journal of Geophysical Research, vol. 104, pp. 6335-6352, 1999.

[23] H. Kato, K. Nishizawa, H. Hirakuchi, S. Kadokura, N. Oshima, and F. Giorgi, "Performance of RegCM2.5/NCAR-CSM nested system for the simulation of climate change in East Asia caused by global warming," Journal of the Meteorological Society of Japan, vol. 79, no. 1, pp. 99-121, 2001.

[24] M. Nicolini, P. Salio, J. J. Katzfey, J. L. McGregor, and A. C. Saulo, "January and July regional climate simulation over South
America," Journal of Geophysical Research D, vol. 107, no. 22, pp. $1-13,2002$.

[25] P. Samuelsson, C. G. Jones, U. Willén et al., “The rossby centre regional climate model RCA3: model description and performance," Tellus A: Dynamic Meteorology and Oceanography, vol. 63, no. 1, pp. 4-23, 2011.

[26] F. Giorgi, E. Coppola, F. Solmon et al., "RegCM4: model description and preliminary tests over multiple CORDEX domains," Climate Research, vol. 52, no. 1, pp. 7-29, 2012.

[27] F. Giorgi and R. O. Anyah, "The road towards RegCM4c," Climate Research, vol. 52, pp. 3-6, 2012.

[28] F. Giorgi and G. T. Bates, "The climatologic al skill of a regional model over complex terrain," Monthly Weather Review, vol. 117, pp. 2325-2347, 1989.

[29] B. Bhaskaran, R. G. Jones, J. M. Murphy, and M. Noguer, "Simulations of the Indian summer monsoon using a nested regional climate model: domain size experiments," Climate Dynamics, vol. 12, no. 9, pp. 573-587, 1996.

[30] J. L. McGregor, "Regional climate modelling," Meteorology and Atmospheric Physics, vol. 63, no. 1-2, pp. 105-117, 1997.

[31] M. de Castro, C. Gallardo, K. Jylha, and H. Tuomenvirta, "The use of a climate-type classification for assessing climate change effects in Europe from an ensemble of nine regional climate models," Climatic Change, vol. 81, no. 1, pp. 329-341, 2007.

[32] U. Heikkilä, A. Sandvik, and A. Sorterberg, "Dynamical downscaling of ERA-40 in complex terrain using WRF regional Climate model," Climate Dynamics, vol. 37, no. 7-8, pp. 15511564, 2011.

[33] D. H. Prasad, J. Wibig, and M. Repaz, "Numerical modeling of the severe cold weather event over Central Europe," Advances in Meteorology, vol. 2010, Article ID 619478, 15 pages, 2010.

[34] D. Hari Prasad, C. Venkata Srinivas, D. Venkata Bhaskar Rao, and Y. Anjaneyulu, "Simulation of Indian monsoon extreme rainfall events during the decadal period 2000-2009 using a high resolution mesoscale model," Advances in Geosciences, vol. A6, pp. 31-48, 2011.

[35] G. Nikulin, E. Kjellström, U. Hansson, G. Strandberg, and A. Ullerstig, "Evaluation and future projections of temperature, precipitation and wind extremes over Europe in an ensemble of regional climate simulations," Tellus A: Dynamic Meteorology and Oceanography, vol. 63, no. 1, pp. 41-55, 2011.

[36] P. Lorenz and D. Jacob, "Validation of temperature trends in the ENSEMBLES regional climate model runs driven by ERA40," Climate Research, vol. 44, no. 2-3, pp. 167-177, 2010.

[37] C. V. Srinivas, D. Hariprasad, D. V. Bhaskar Rao, Y. Anjaneyulu, R. Baskaran, and B. Venkatraman, "Simulation of the Indian summer monsoon regional climate using advanced research WRF model," International Journal of Climatology, vol. 33, no. 5, pp. 1195-1210, 2013.

[38] E. Kjellström, F. Boberg, M. Castro, H. J. Christensen, G. Nikulin, and E. Sánchez, "Dailyand monthly temperature and precipitation statistics as performance indicators for regionalclimate models," Climate Research, vol. 44, no. 2-3, pp. 135-150, 2010.

[39] P. Van der Linden and J. F. B. Mitchell, ENSEMBLES: Climate Change and Its Impacts: Summry of Research and Results from ENSEMBLES Project, Met Office Hadley Center, Exter, UK, 2009.

[40] S. M. Uppala, P. W. allberg, A. J. Simmons, U. Andrae, and V. da Costa Bechtold, “The ERA-40 re-analysis," Quarterly Journal of the Royal Meteorological Society, vol. 131, pp. 2961-3012, 2005. 
[41] J. H. Christensen, E. Kjellström, F. Giorgi, G. Lenderink, and M. Rummukainen, "Weight assignment in regional climate models," Climate Research, vol. 44, pp. 179-194, 2010.

[42] E. Kjellström, F. Boberg, M. Castro, H. J. Christensen, G. Nikulin, and E. Sánchez, "Daily and monthly temperature and precipitation statistics as performance indicators for regional climate models," Climate Research, vol. 44, pp. 135-150, 2010.

[43] S. A. Rauscher, E. Coppola, C. Piani, and F. Giorgi, "Resolution effects on regional climate model simulations of seasonal precipitation over Europe," Climate Dynamics, vol. 35, no. 4, pp. 685-711, 2010.

[44] F. Boberg, P. Berg, P. Thejll, W. J. Gutowski, and J. H. Christensen, "Improved confidence in climate change projections of precipitation further evaluated using daily statistics from ENSEMBLES models," Climate Dynamics, vol. 35, no. 7, pp. 1509-1520, 2010.

[45] E. Sanchez-Gomez, S. Somot, and M. Déqué, "Ability of an ensemble of regional climate models to reproduce weather regimes over Europe-Atlantic during the period 1961-2000," Climate Dynamics, vol. 33, no. 5, pp. 723-736, 2009.

[46] G. Lenderink, "Exploring metrics of extreme daily precipitation in a large ensemble of regional climate model simulations," Climate Research, vol. 44, no. 2-3, pp. 151-166, 2010.

[47] P. M. M. Soares, R. M. Cardoso, P. M. A. Miranda, P. Viterbo, and M. Belo-Pereira, "Assessment of the ENSEMBLES regional climate models in the representation of precipitation variability and extremes over Portugal," Journal of Geophysical Research, vol. 117, no. D7, article 16, 2012.

[48] U. Heikkilä, A. Sandvik, and A. Sorteberg, "Dynamical downscaling of ERA-40 in complex terrain using the WRF regional climate model," Climate Dynamics, vol. 37, no. 7-8, pp. 1551-1564, 2011.

[49] R. M. Cardoso, P. M. M. Soares, P. M. A. Miranda, and M. Belo-Pereira, "WRF high resolution simulation of Iberian mean and extreme precipitation climate," International Journal of Climatology, vol. 33, no. 11, pp. 2591-2608, 2013.

[50] E. Kalnay, M. Kanamitsu, R. Kistler et al., "The NCEP/NCAR 40-year reanalysis project," Bulletin of the American Meteorological Society, vol. 77, no. 3, pp. 437-471, 1996.

[51] J. Dudhia, "Numerical study of convection observed during the Winter Monsoon Experiment using a mesoscale twodimensional model," Journal of the Atmospheric Sciences, vol. 46, no. 20, pp. 3077-3107, 1989.

[52] E. J. Mlawer, S. J. Taubman, P. D. Brown, M. J. Iacono, and S. A. Clough, "Radiative transfer for inhomogeneous atmospheres: RRTM, a validated correlated-k model for the longwave," Journal of Geophysical Research D: Atmospheres, vol. 102, no. 14, pp. 16663-16682, 1997.

[53] Y. Noh, W. G. Cheon, S. Y. Hong, and S. Raasch, "Improvement of the K-profile model for the planetary boundary layer based on large eddy simulation data," Boundary-Layer Meteorology, vol. 107, no. 2, pp. 401-427, 2003.

[54] S. Hong, Y. Noh, and J. Dudhia, "A new vertical diffusion package with an explicit treatment of entrainment processes," Monthly Weather Review, vol. 134, no. 9, pp. 2318-2341, 2006.

[55] A. K. Betts and M. J. Miller, "A new convective adjustment scheme. Part II: single column tests using GATE wave, BOMEX, ATEX and arctic air-mass data sets," Quarterly Journal of Royal Meteorological Society, vol. 112, no. 473, pp. 693-709, 1986.

[56] Z. I. Janjic, "Comments on development and evaluation of a convection scheme for use in climate models," Journal of Atmospheric Science, vol. 57, p. 3686, 2000.
[57] M. R. Haylock, N. Hofstra, A. M. G. Klein Tank, E. J. Klok, P. D. Jones, and M. New, "A European daily high-resolution gridded data set of surface temperature and precipitation for 1950-2006," Journal of Geophysical Research D: Atmospheres, vol. 113, no. 20, Article ID D20119, 2008.

[58] A. H. Murphy and R. L. Winkler, "A general framework for forecast verification," Monthly Weather Review, vol. 115, no. 7, pp. 1330-1338, 1987.

[59] J. E. Nash and J. V. Sutcliffe, "River flow forecasting through conceptual models part I-a discussion of principles," Journal of Hydrology, vol. 10, no. 3, pp. 282-290, 1970.

[60] D. N. Moriasi, J. G. Arnold, M. W. Van Liew, R. L. Bingner, R. D. Harmel, and T. L. Veith, "Model evaluation guidelines for systematic quantification of accuracy in watershed simulations," Transactions of the ASABE, vol. 50, no. 3, pp. 885-900, 2007.

[61] WMO, "Climate monitoring and assessment definition of climate extreme events," in Proceedings of the Commission for Climatology Management Group Meeting, pp. 18-21, Geneva, Switzerland, 2010.

[62] R. Laprise, R. de Elía, D. Caya et al., "Challenging some tenets of regional climate modeling," Meteorology and Atmospheric Physics, vol. 100, pp. 3-22, 2008.

[63] M. Garcia-Diez, J. Fernandez, L. Fita, and C. Yague, "Seasonal dependence of WRF model biases and sensitivity to PBL schemes over Europe," Quarterly Journal of the Royal Meteorological Society, vol. 139, pp. 501-514, 2013. 

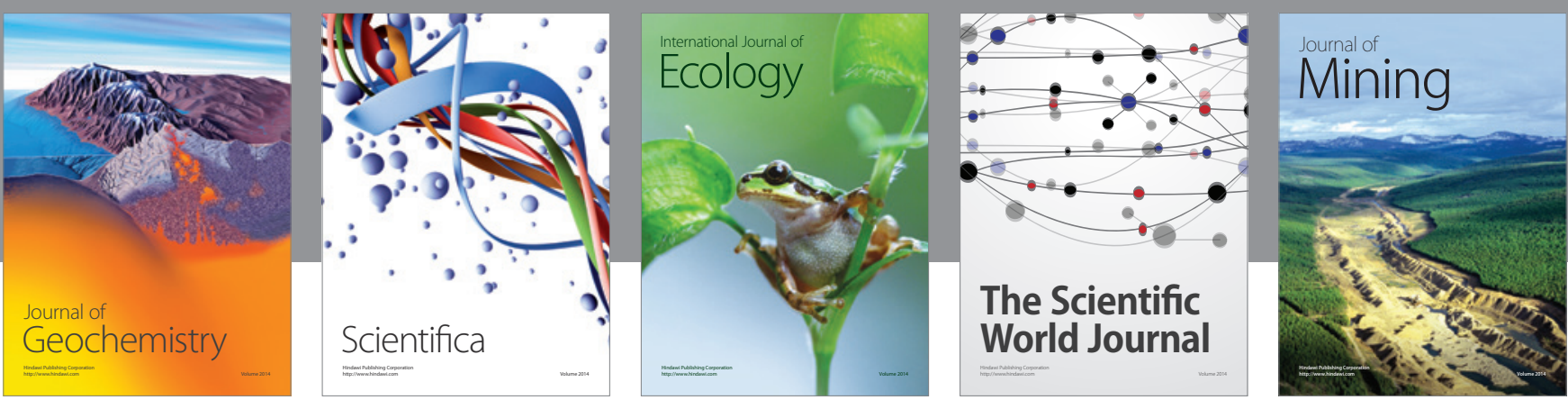

The Scientific World Journal
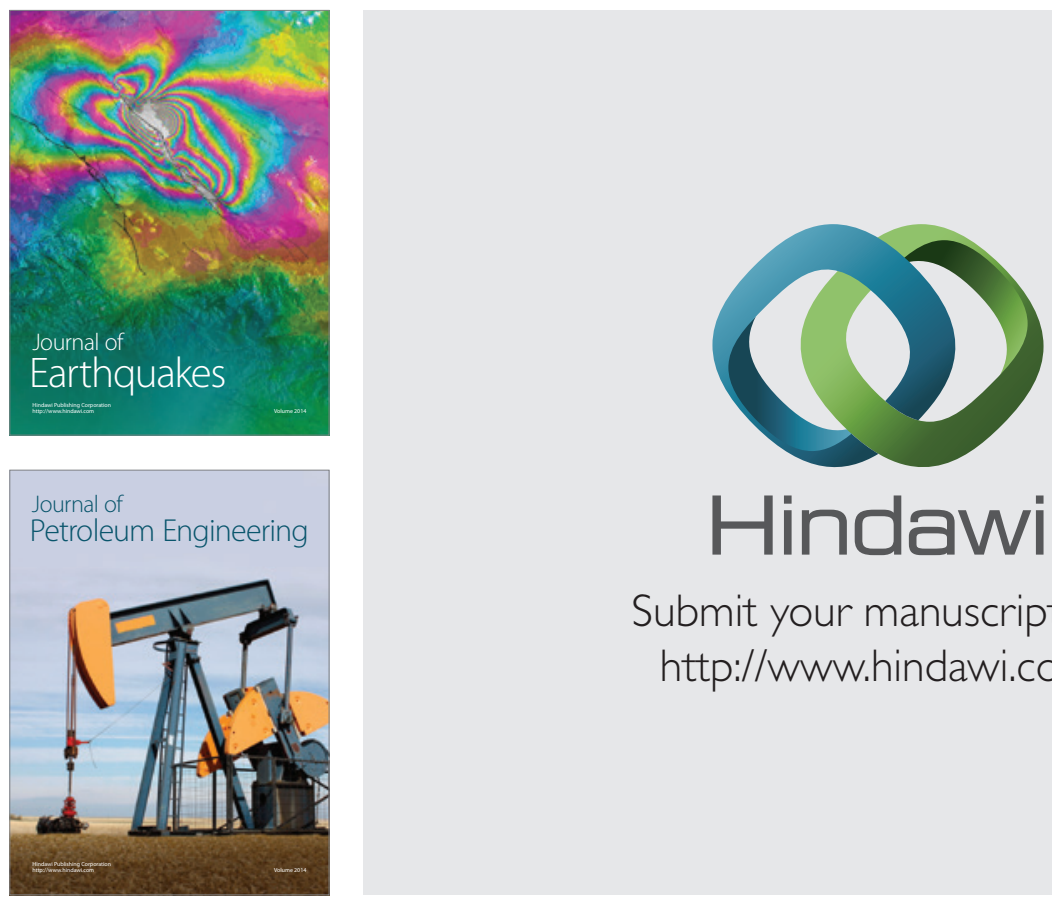

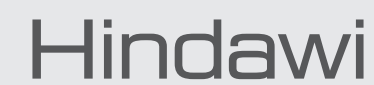

Submit your manuscripts at

http://www.hindawi.com
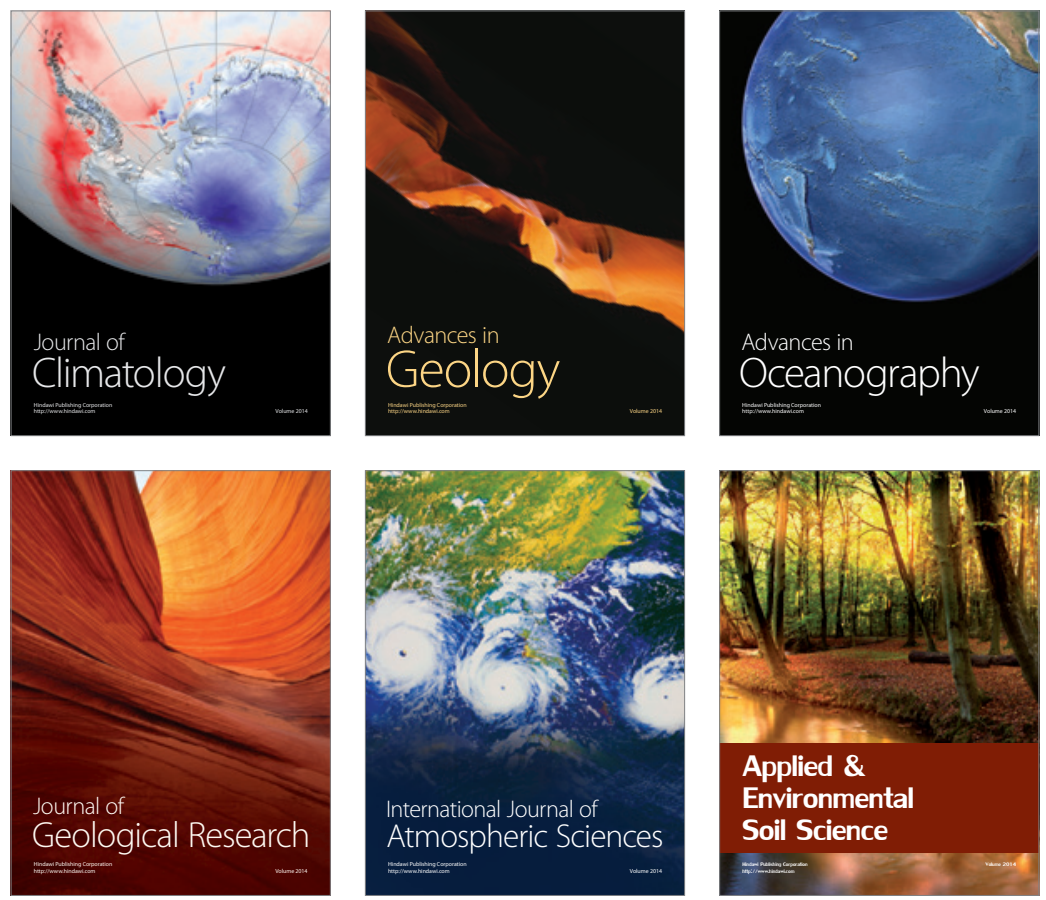
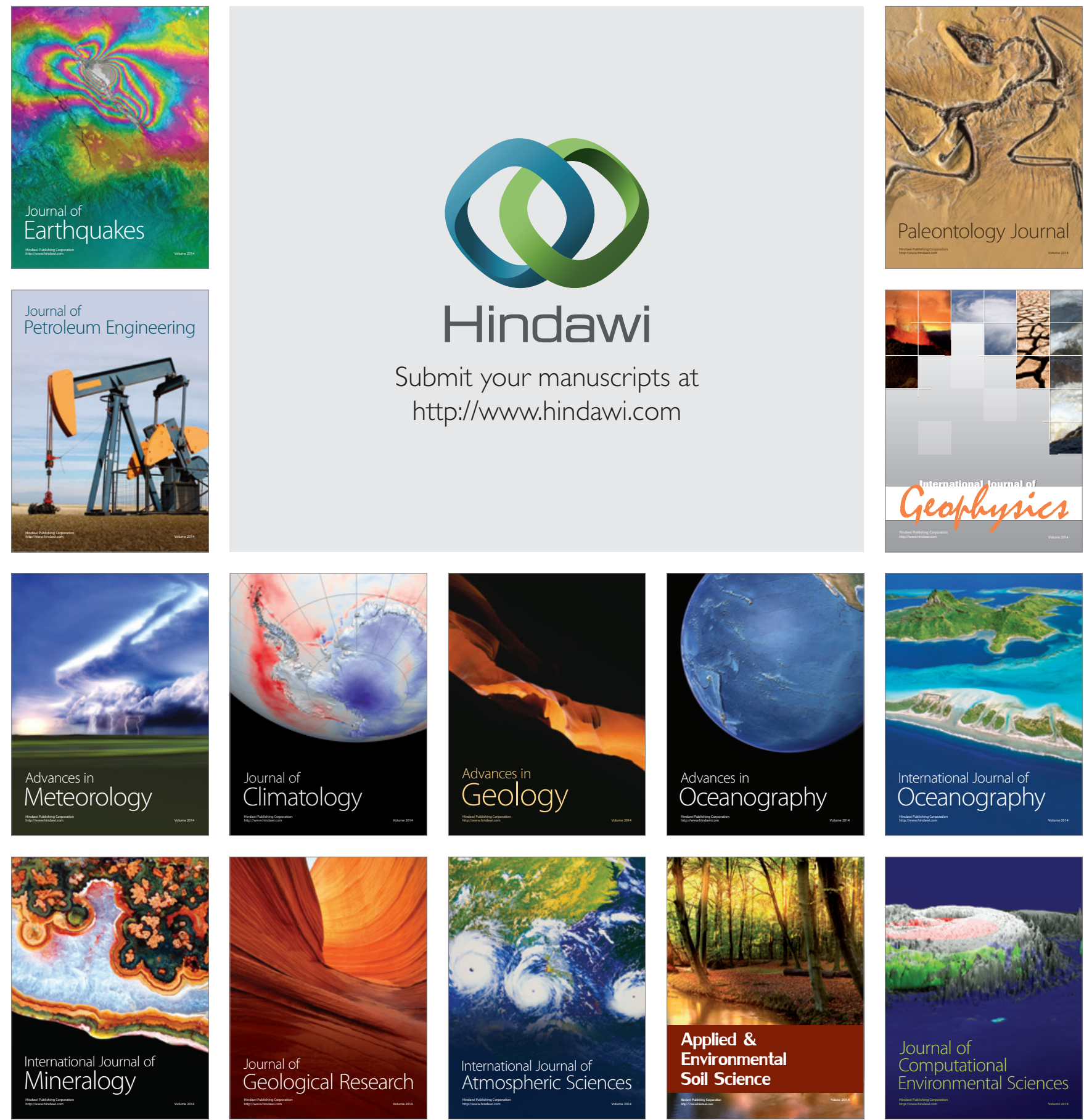